\title{
A trait-based approach to comparative functional plant ecology: concepts, methods and applications for agroecology. A review
}

\author{
Eric Garnier • Marie-Laure Navas
}

Accepted: 25 November 2010 /Published online: 11 August 2011

(C) INRA and Springer Science+Business Media B.V. 2011

\begin{abstract}
Comparative functional ecology seeks to understand why and how ecological systems and their components operate differently across environments. Although traditionally used in (semi)-natural situations, its concepts and methods could certainly apply to address key issues in the large variety of agricultural systems encountered across the world. In this review, we present major advances in comparative plant functional ecology that were made possible over the last two decades by the rapid development of a trait-based approach to plant functioning and prospects to apply it in agricultural situations. The strength of this approach is that it enables us to assess the interactions between organisms and their environment simultaneously on a large number of species, a prerequisite to address questions relative to species distribution, community assembly and ecosystem functioning. The trait concept will be first defined, before presenting a conceptual framework to understand the effects of environmental factors on plant community structure and ecosystem properties via plant traits. We will then argue that leading dimensions of variation among species can be captured by some selected traits and show that a combination of three easily measured traits - specific leaf area (the ratio of leaf area to leaf dry mass), plant height and seed mass - enables us to assess how different species use their resources, interact with
\end{abstract}

\section{E. Garnier $(\bowtie)$}

CNRS, Centre d'Ecologie Fonctionnelle et Evolutive (UMR 5175), 1919 Route de Mende,

34293 Montpellier Cedex 5, France

e-mail: eric.garnier@cefe.cnrs.fr

M.-L. Navas

Montpellier SupAgro,

Centre d'Ecologie Fonctionnelle et Evolutive (UMR 5175),

1919 Route de Mende,

34293 Montpellier Cedex 5, France neighbours and disperse in time and space. The use of traits to address central questions in community ecology will be reviewed next. It will be shown that traits allow us to (1) understand how plant species are sorted according to the nature of environmental gradients, (2) evaluate the relative importance of habitat filtering and limiting similarity in the process of community assembly and (3) quantify two main components of community functional structure, namely, community-weighted means of traits and community functional divergence. The relative impacts of these two components on ecosystem properties will then be discussed in the case of several components of primary productivity, litter decomposition, soil water content and carbon sequestration. There is strong support for the biomass ratio hypothesis, which states that the extent to which the traits of a species affect those ecosystem properties depends on the abundance of this species in the community. Assessing the role of functional divergence among species on ecosystem properties will require major methodological breakthroughs, both in terms of metrics and statistical procedures to be used. In agricultural situations, we show that trait-based approaches have been successfully developed to assess the impacts of management practices on (1) the agronomic value of grasslands and (2) the functional composition and structure of crop weed communities and how these could affect the functioning of the crop. Applications in forestry are still poorly developed, especially in temperate regions where the number of species in managed forest remains relatively low. The last decades of research have led to the constitution of large data sets of plant traits, which remain poorly compatible and accessible. Recent advances in the field of ecoinformatics suggest that major progress could be achieved in this area by using improved metadata standards and advancing trait domain ontologies. Finally, concluding remarks, 
unanswered questions and directions for research using the functional approach to biodiversity made possible by the use of traits will be discussed in the contexts of ecological and agronomical systems. The latter indeed cover a wide range of environmental conditions and biological diversity, and the prospect for reducing environmental impacts in highly productive, lowdiversity systems will certainly imply improving our skills for the management of more diverse systems prone to a trait-based approach as reviewed here.

Keywords Agroecology · Biodiversity . Community structure - Comparative ecology · Ecoinformatics . Ecological strategy $\cdot$ Ecosystem properties $\cdot$ Environmental conditions $\cdot$ Functional diversity $\cdot$ Plant functional trait

\section{Contents}

1. Introduction: a trait-based approach to comparative functional ecology . . . . . . . . . . . . . 2

2. Definitions and a framework ............. 3 2.1. What is a trait ?............ 3 2.2. A response-and-effect framework . . . . . . . . . 4

3. A functional characterization of plants . . . . . . . . . 5

3.1. The resource use dimension . . . . . . . . . 6

3.2. The height dimension ............. . 8

3.3. The seed size dimension ............ . 10

3.4. Beyond a three dimensional scheme . . . . . . . 11

4. A functional approach to plant community structure . . . . . . . . . . . . . . . . . 11

4.1. Environmental gradients and response traits . . . 11

4.2. Assembly rules and environmental filters . . . . . 12

4.3. Assembly rules and trait distribution within communities . . . . . . . . . . . . . . 13

4.4. Phylogeny, traits and community assembly . . . 13

5. Traits and ecosystem properties ........... 15

5.1. The biomass ratio hypothesis: community-level weighed means of traits . . . . . . . . . . 15 5.1.1. Components of primary productivity . . . 16 5.1.2. Decomposition and accumulation of litter................... 17

5.1.3. Soil water content . . . . . . . . . . . . . 17

5.1.4. Other components of biogeochemical cycles. . . . . . . . . . . . . . 18

5.2. Complementarity among species: incorporating functional divergence . . . . . . . . . . . . . 19

5.3. The role of plant traits on ecosystem properties in controlled experiments . . . . . . . . . . . 20

5.4. A different perspective: ecosystem allometry . . . . 21

6. Plant traits in agricultural and forestry contexts. . . . 21

6.1 Grasslands . . . . . . . . . . . . . . . . . . 21

6.2 Crop weed communities . . . . . . . . . . . . . 22
6.3. Forests . . . . . . . . . . . . . . . . 23

7. Trait databases and ecoinformatics . . . . . . . . 24

7.1. Availability of trait data . . . . . . . . . 24

7.2. Towards a trait-based ecoinformatics . . . . . 24

8. Conclusions and perspectives ........... 25

\section{Introduction: a trait-based approach to comparative functional ecology}

A prominent field of research in functional ecology seeks to understand why and how ecological systems and their components operate differently across environments (e.g. Calow 1987; Duarte et al. 1995; Westoby 1999; Pugnaire and Valladares 2007). The comparative approach is thus consubstantial to this field of ecology (e.g. Bradshaw 1987; Keddy 1992b; Westoby 1999). If we are to understand questions such as why and how are functions coordinated within organisms?, why and how do different species perform differently along ecological gradients?, why and how do species interact within a community? and why and how do species affect the functioning of ecosystems?, comparing species is an absolute necessity. Keddy (1992b) and Westoby (1999) also argue that, for at least two reasons, such comparisons should be conducted on a large number of species. First, in the struggle to find broad generalisations, we have to make sure that the patterns observed are not simple peculiarities of the species examined. Second, the tests of relationships between species and environment and/or ecosystem functioning need to be statistically powerful and robust. As stressed by Keddy (1992b), this approach is literally orthogonal to that followed in population ecology where many aspects pertaining to population dynamics are assessed in relatively few species. There is also no reason why the comparative approach could not apply to the large variety of agricultural systems encountered across the world (e.g. Swift and Anderson 1993; Malézieux et al. 2009). These systems indeed cover a wide range of environmental conditions and biological diversity, and the prospect for reducing environmental impacts in highly productive, lowdiversity systems (Giller et al. 1997; Wezel et al. 2009; Griffon 2010) will certainly imply improving our skills for the management of more diverse systems.

There is a growing consensus that a trait-based approach has a strong potential to address several of the issues introduced above. A non-exhaustive list includes (1) the functioning of organisms and how it relates to the environment (e.g. Grime 1979; Chapin et al. 1993; Grime et al. 1997; Westoby et al. 2002), (2) the understanding of unsolved questions in community ecology such as the identification of rules governing the assembly of communities (McGill et al. 2006; Suding et al. 2008; Shipley 2010) and (3) the 
understanding of how the functioning of organisms scales up to that of ecosystems (Reich et al. 1992; Chapin 1993; Lavorel and Garnier 2002) and controls some of the services they deliver to humans (Díaz et al. 2006; Díaz et al. 2007b), including those delivered by agriculture. As measurable properties of individuals related to their functioning and modulating their fitness (McGill et al. 2006; Violle et al. 2007b) (Fig. 1 and see Section 2), traits enable us to capture the interactions between organisms and their environment (both abiotic and biotic) and bring a functional perspective to the study of controls on biodiversity and how it affects processes at higher levels of organisation.

The aim of this review is to present the rationale for the traitbased approach and how it can be used to address some pending questions in functional ecology. It will be restricted to the case of terrestrial plants, to which a large amount of research has been devoted in the last 20 years (Lavorel et al. 2007). We will first discuss what a trait is, before showing which are some of the most relevant traits widely utilised to characterise plant functioning. We will then present recent developments in community and ecosystem ecology based on the use of traits. This will be largely, but not exclusively, based on the response-effect framework proposed by Lavorel and Garnier (2002) and further refined by Suding et al. (2008). Response traits are those which show a consistent response to a particular environmental factor, while effect traits are those which have a similar effect on one or several ecosystem functions (Lavorel and Garnier 2002 and references therein). We will then present examples of various traitbased approaches in the context of agronomic and forestry applications in selected temperate systems. The wealth of research devoted to plant traits has generated large amounts of data, leading to the imperious need of devising systems allowing potential users to access and value these data. Some key steps that will make this possible in the near future will then be presented, before concluding remarks will be proposed to close this review.

\section{Definitions and a framework}

\subsection{What is a trait?}

A thorough analysis of the literature reveals that the term 'trait' has been used in somewhat different meanings in the field of ecology and population biology (Violle et al. 2007b). Here, we will stick to the idea that it should be measured at the level of an individual organism (McGill et al. 2006; Lavorel et al. 2007), with the following definition: 'any morphological, physiological or phenological feature measurable at the individual level, from the cell to the whole-organism level, without reference to the environment or any other level of organization' (Violle et al. 2007b). This definition implies that no information external to the individual (environmental factors) or at any other level of organisation (population, community or ecosystem) is required to define a trait. Figure 1 shows examples of traits, which may be actual functions related to, e.g. reproduction (fecundity, dispersal, etc.) or vegetative growth (light interception, nutrient uptake, etc.), or traits related to these functions but which are more easily measured ('functional markers' sensu Garnier et al. 2004).

\section{Functions}

Fecundity
Dispersal
Recruitment
Light interception
Competitive ability

Resource acquisition/growth Litter decomposition

Absorption (nutrients, water) Carbon fluxes (exsudation...) Underground competition

\section{«Functional markers »}

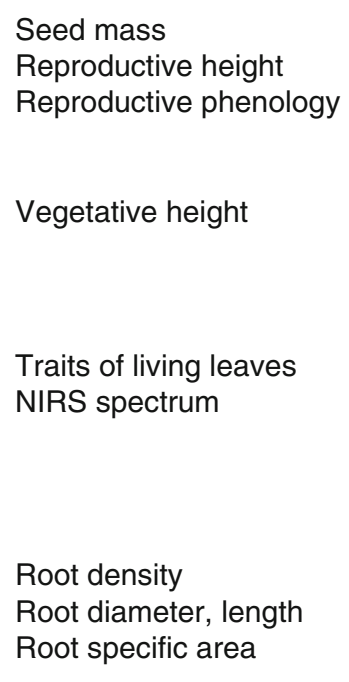

Fig. 1 Examples of functions and related functional markers. NIRS near-infrared spectroscopy. Hand drawing of Euphorbia helioscopia by Baptiste Testi. Recomposed from Lavorel et al. (2007) 
As discussed by Violle et al. (2007b), the definition given above requires further precisions: (1) the particular value or modality taken by the trait at any place and time is called an 'attribute' (Lavorel et al. 2007); (2) within a species, the trait, either continuous or categorical, may show different attributes along environmental gradients or through time (seasonal and ontogenic variation); (3) the attribute for a trait is usually assessed for one population (average of attributes of a set of individuals) in space and time. The latter assertion has two consequences: first, there is not a single-trait attribute for any particular species, and assessing intra- vs. inter-specific variability of traits is clearly of interest in this context (Garnier et al. 2001a; Cornelissen et al. 2003a; Roche et al. 2004; Mokany and Ash 2008; Albert et al. 2010); second, information on the local environment where the trait has been measured is essential to interpret the ecological/ evolutionary meaning of trait attributes (McGill et al. 2006; Bartholomeus et al. 2008), even if this information is not compulsory to define a trait.

Applying Arnold's (1983) 'morphology, performance, fitness' paradigm to plants, Violle et al. (2007b) further discussed the value of introducing a hierarchical perspective on plant traits. They suggested that the three components of plant fitness (growth, survival and reproduction) be characterised by the three 'performance traits': vegetative biomass, reproductive output and plant survival, while the morphological, phenological and physiological traits that influence these three performance traits be called 'functional traits'. Although inferred in many ecological studies, the relationships between functional and performance traits, and hence fitness, is actually seldom demonstrated (cf. Ackerly and Monson 2003).

Although the approach presented above takes an ecological perspective on traits, it should be borne in mind that, since all species have a common ancestor at some point in their evolutionary history, there will always be some degree of similarity between species traits related to their common ancestry (cf. Silvertown et al. 1997 and references therein). Trait conservatism might arise at different depths of the phylogeny, but some ecologically relevant traits may be labile towards the tip of the phylogeny (e.g. Cavender-Bares et al. 2009). Several studies have recently addressed these issues, which was made possible by the increasing availability of phylogenetic data and the accumulation of broad comparative data sets. As an example, Fig. 2 presents the distribution of leaf mass per area (LMA, the ratio of leaf mass to area, see Section 3.1) with respect to the major clades of the Tracheophytes, showing that divergence between gymnosperms and angiosperms is a major contributor to the present-day spread of this trait (Flores et al., submitted manuscript). Comparable studies have been conducted on several other traits, including seed mass (Moles et al. 2005b) and leaf chemical elements (Watanabe et al. 2007).
The future development of such analyses on a broad range of traits should help teasing out the phylogenetic from the ecological signal on trait values of extant species.

\subsection{A response-and-effect framework}

The response-and-effect framework around which most of this review articulates involves several components and steps as shown in Fig. 3. In this scheme, a species is represented by two sets of connected traits (same symbol but different colours) to acknowledge the fact that some sets of traits might vary independently from one another across species (as is the case for, e.g. vegetative and regenerative traits: cf. Grime 2001). The upper part of Fig. 3 shows the range of values displayed for these two types of traits within a species pool found in a particular geographical region and from which local communities assemble (cf. Belyea and Lancaster 1999). From this pool, the habitat filter, which involves both abiotic and biotic components, is assumed to sort species according to their attributes (based on Woodward and Diament 1991; Keddy 1992a; Grime 2006; Suding et al. 2008; Cornwell and Ackerly 2009). Habitat filtering acts in reducing the range of attributes (double horizontal line in Fig. 3) compared to that present in the species pool, thereby inducing convergence in trait values. By contrast, the process of limiting similarity affects the spacing of trait values (trait divergence: simple horizontal line in Fig. 3), with two possible hypotheses. Hypothesis 1 assumes that both habitat filtering due to environmental factors and limiting similarity affect the same set of traits; this may happen when filtering is due, e.g. to resource limitation and when competitive interactions among individuals are strong. Hypothesis 2 postulates that different sets of traits are involved in the two processes; this may happen when limiting similarity is induced by disturbances (Grime 2006; Navas and Violle 2009, and see Sections 4.2 and 4.3 for further discussion). The relative strengths of the habitat filter and limiting similarity is expected to depend on the identity of the trait in combination with the particular abiotic conditions at a site. Traits associated with the response of organisms to these abiotic and biotic factors are called 'response traits' (cf. Lavorel and Garnier 2002).

The bottom part of the scheme (from the two lateral bended arrows downwards) presents hypotheses pertaining to the relationships between community structure and ecosystem properties (EP, hereafter; a list of abbreviations used in the review is given in Table 1) (based on Chapin et al. 2000; Loreau et al. 2001; Lavorel and Garnier 2002; Suding et al. 2008). These EP pertain both to compartments (represented by symbols in the box at the bottom of Fig. 3), such as standing biomass or soil water content, and fluxes within or between compartments, such 


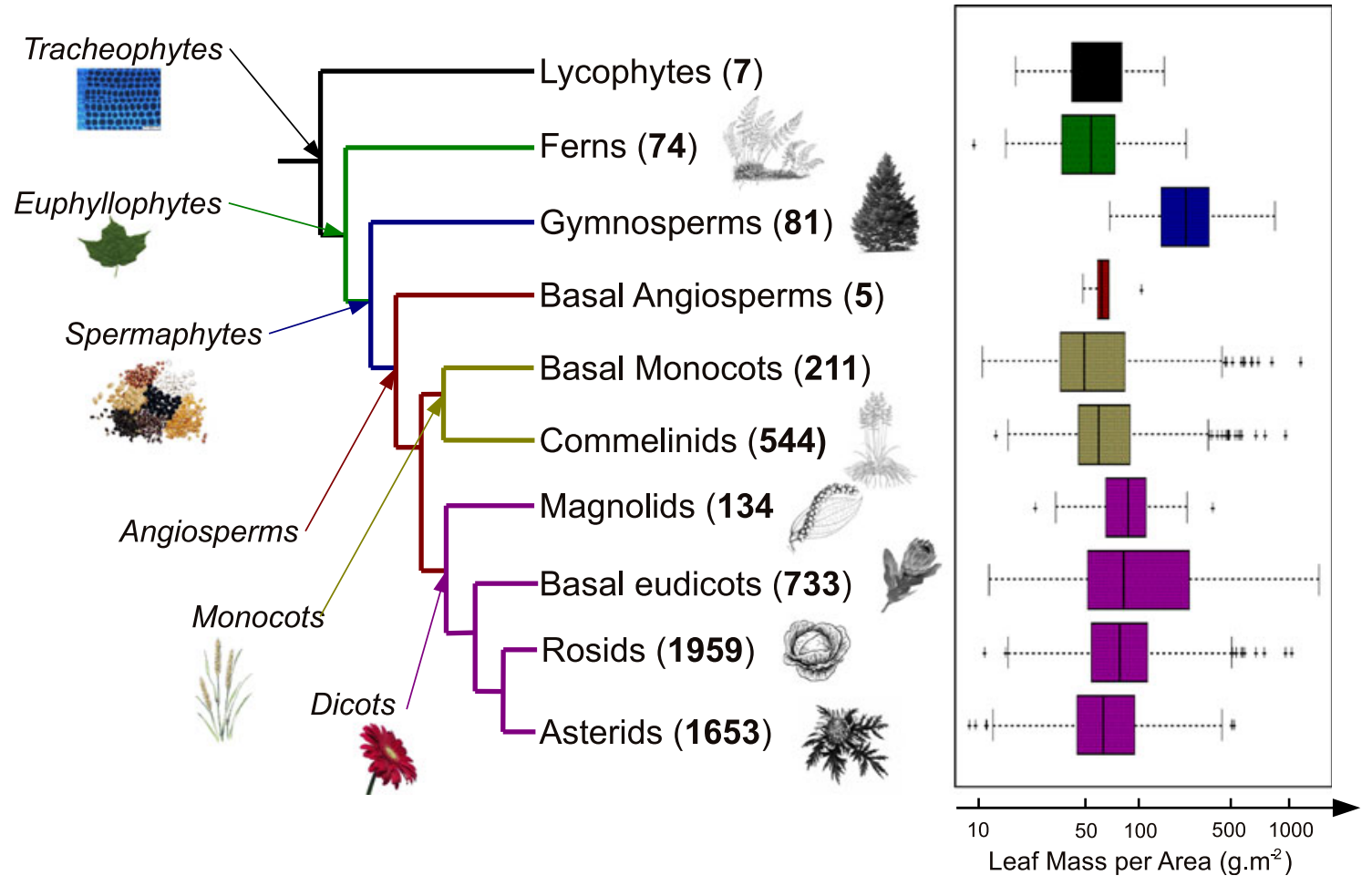

Fig. 2 Phylogeny of LMA (the ratio of leaf mass to leaf area, the inverse of SLA: for further discussion, see Section 2.1) for major clades of Tracheophytes (data from Flores et al., submitted manuscript). Numbers between brackets show the number of species in each clade

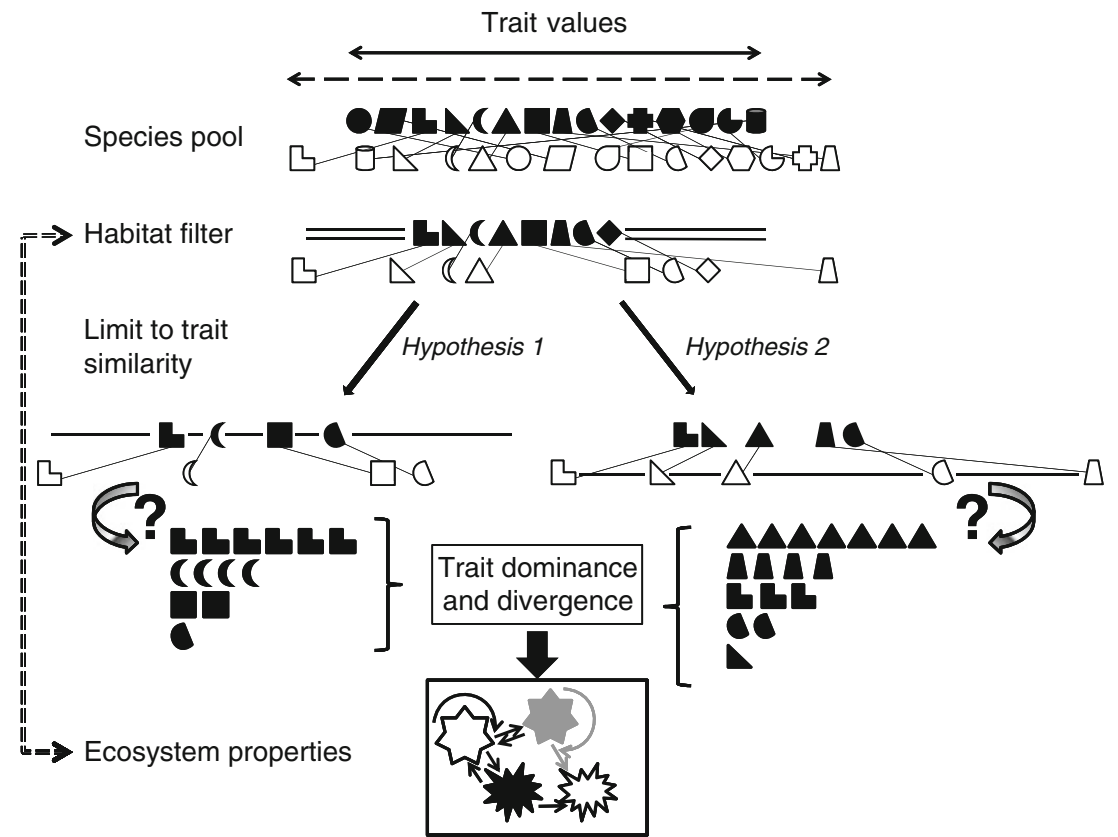

Fig. 3 A response-and-effect framework for effects of environmental factors on plant community structure and ecosystem properties (EP) via plant traits. In this scheme, a species is represented by two sets of connected traits with the same symbol but different colours. The upper part of the scheme (down to the two lateral bended arrows) presents hypotheses for assembly effects on within-community trait distribution (based on Woodward and Diament 1991; Keddy 1992a; Grime 2006; Suding et al. 2008; Cornwell and Ackerly 2009). The bottom part of the scheme (from the two lateral bended arrows downwards) presents hypotheses pertaining to the relationships between community structure and EP (box at the bottom of the figure): compartments (e.g. standing biomass or soil water content), represented by symbols, and fluxes (e.g. primary productivity or decomposition of litter) within or between compartments, represented by arrows (based on Chapin et al. 2000; Loreau et al. 2001; Lavorel and Garnier 2002; Suding et al. 2008). Direct effects of habitat filters on EP as well as potential feedbacks are symbolised by the double-dotted arrow on the left-hand side of the scheme. See Section 2.2 for further explanations 
Table 1 List of abbreviations used in the text

\begin{tabular}{|c|c|c|}
\hline Category & Abbreviation & Meaning \\
\hline \multirow[t]{12}{*}{ Trait } & LDMC & Leaf dry matter content \\
\hline & LLS & Leaf life span \\
\hline & $\mathrm{LNC}$ & Leaf nitrogen concentration \\
\hline & LPC & Leaf phosphorus concentration \\
\hline & $L_{\text {root }}$ & Root length \\
\hline & LMA & Leaf mass per area \\
\hline & $\mathrm{PS}_{\mathrm{m}}$ & Mass-based maximum photosynthetic rate \\
\hline & RGR & Relative growth rate \\
\hline & $\mathrm{RGR}_{\max }$ & Maximum relative growth rate \\
\hline & SLA & Specific leaf area \\
\hline & SRA & Specific root area \\
\hline & SRL & Specific root length \\
\hline \multirow[t]{7}{*}{ Ecosystem properties } & $\mathrm{AGB}_{\max }$ & Maximum above-ground standing biomass \\
\hline & ANPP & Above-ground net primary productivity \\
\hline & BNCS & Below-ground net carbon storage \\
\hline & EP & Ecosystem properties \\
\hline & NPP & Net primary productivity \\
\hline & SNPP & Specific net primary productivity \\
\hline & SOC & Soil organic carbon content \\
\hline \multirow[t]{7}{*}{ Others } & $\mathrm{BRH}$ & Biomass ratio hypothesis \\
\hline & CWM & Community-level weighted mean of trait \\
\hline & CFP & Community functional parameter \\
\hline & FD & Functional diversity \\
\hline & FDvg & Functional divergence \\
\hline & Glopnet & Global Plant Trait Network \\
\hline & LES & Leaf economics spectrum \\
\hline
\end{tabular}

as primary productivity or decomposition of litter (arrows on Fig. 3). EP are assumed to depend on at least two components of community functional diversity (FD): attribute dominance and attribute divergence, which both relate to the shape of the trait value distribution within the community (see Sections 4 and 5). Those particular traits that determine the effects of plants on ecosystem functions, such as biogeochemical cycling or propensity to disturbance, are called 'effect traits' (cf. Lavorel and Garnier 2002). The two bended arrows point to two examples of species abundance distributions for a single trait, likely to induce different trait distributions (not shown on the figure). The question marks next to these arrows point to the lack of sound hypotheses and knowledge linking presence/absence of species in a community and their abundance distribution. Finally, direct effects of habitat filters on EP as well as potential feedbacks are symbolised by the double-dotted arrow on the left-hand side of the scheme.

The following sections will illustrate and discuss various aspects of this scheme. We will begin by a prominent research area for functional traits, which can be thought of as developing a short list of trait dimensions (Westoby et al.
2002), allowing us to grasp a functional perspective on the diversity of organisms.

\section{A functional characterisation of plants}

Among the wealth of traits measurable on an individual, those of interest to comparative functional ecology must fill at least four conditions (Lavorel et al. 2007; Fig. 1). They should (1) bear some relationship to plant function, (2) be relatively easy to observe and quick to quantify ('functional markers': Garnier et al. 2004), (3) be measurable using standardised protocols across a wide range of species and growing conditions (Hendry and Grime 1993; Cornelissen et al. 2003b; Knevel et al. 2005) and (4) have a consistent ranking - not necessarily constant absolute values - across species when environmental conditions vary (Garnier et al. 2001a; Cornelissen et al. 2003a; Mokany and Ash 2008).

Identifying such measurable traits provide the means to compare species worldwide. However, individual traits should not be considered in isolation because pairs or groups of traits often co-vary (Chapin et al. 1993; Grime et 
al. 1997; Reich et al. 1997, see Section 3.1). As recognised by early work (Theophrastus ca. 300 BC; Raunkiaer 1934), growth and life forms are one expression of such covariations among traits, although there is actually an important range of variation in trait values and covariation among traits within each growth/life form. More generally, quantifying these co-variations and asking why some sets of traits are sufficiently closely coordinated lead to the identification of single dimensions of strategy variation (Grime 2001; Westoby et al. 2002). Opinions vary, but three such dimensions are now widely accepted as important to plant functioning and ecological strategies (Westoby 1998; Westoby et al. 2002): resource use, height and seed size. These are detailed below.

\subsection{The resource use dimension}

Persistence in a site depends to a large extent on how individuals use (i.e. acquire, retain and loose) their resources. The functioning of green leaves is of prime importance since it sets the pace of carbon input in the plants (and ecosystems) and controls many aspects of plant metabolism.

A fundamental trade-off between fast acquisition rate and efficient conservation of resources has been discussed in the ecological literature for the last four decades (Small 1972; Grime 1977; Chapin 1980; Berendse and Aerts 1987; Reich et al. 1992). However, only in the last 15 years or so has the availability of large sets of data allowed us to quantify these trade-offs and

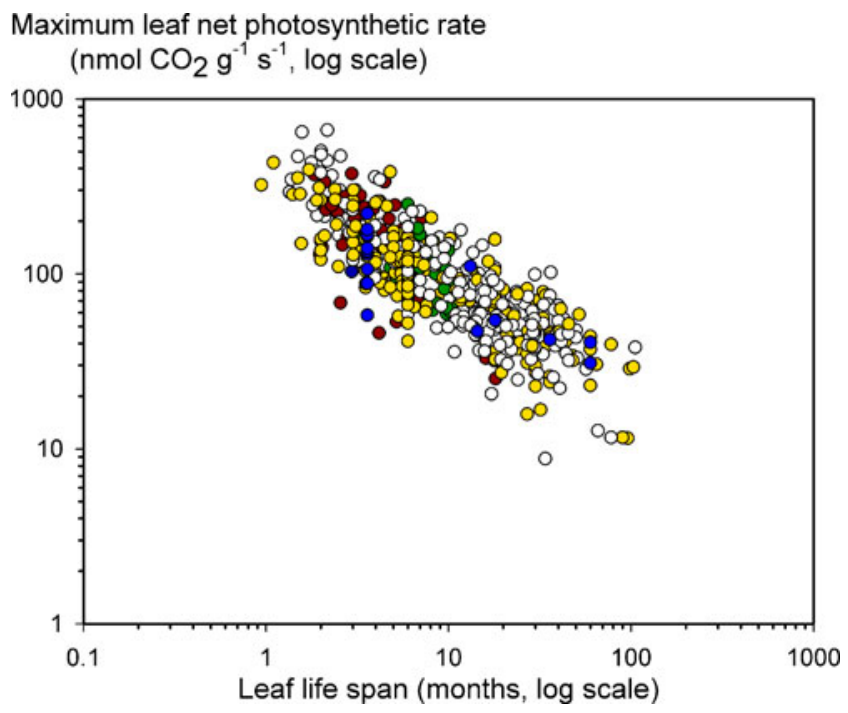

Fig. 4 Relationship between LLS and maximum leaf photosynthetic rate in the Glopnet data set (for details, see Section 3.1). Each point represents a species, and colours are for different biomes: yellow tropical forests, green temperate forests, blue arctic tundra, dark purple Mediterranean garrigue. Correlation coefficient, -0.82 $(P<0.001, n=512)$. Data from Wright et al. (2004) identify the trait syndrome that could be used to describe it on a broad scale (Grime et al. 1997; Reich et al. 1997; Wright et al. 2004). A worldwide survey conducted by the Global Plant Trait Network (Glopnet) on individuals of more than 2,500 species growing under field conditions for six leaf traits - mass-based maximum photosynthetic rate $\left(\mathrm{PS}_{\mathrm{m}}\right)$, dark respiration rate, leaf life span (LLS), specific leaf area (SLA, the ratio of leaf area to leaf mass), leaf nitrogen and phosphorus concentrations (LNC and LPC, respectively), further expanded to leaf potassium concentration (Wright et al. 2005) — shows a negative correlation between PS $_{\mathrm{m}}$ and LLS, largely independent of growth form, plant functional type or biome (Wright et al. 2004; Fig. 4). Rapid photosynthesis tends to be associated with high specific nutrient (at least nitrogen) uptake and high relative growth rate (RGR; Poorter and Garnier 2007 and references therein), while a long LLS relates to a long residence time of nutrients (the average time a molecule remains in the plant once it has been taken up: Berendse and Aerts 1987) within the plant (Berendse and Aerts 1987; Garnier and Aronson 1998; Eckstein et al. 1999; Aerts and Chapin 2000; Kazakou et al. 2007). Leaf photosynthetic rate and life spans are, therefore, two traits that can be used to assess the position of species on the acquisition/conservation trade-off. The Glopnet data set also showed that $\mathrm{PS}_{\mathrm{m}}$ and LLS were, respectively, positively and negatively related to SLA, LNC and LPC and leaf respiration rate (Wright et al. 2004), while leaf potassium concentration was only loosely related to these various traits (Wright et al. 2005). Hence, the idea of a worldwide 'leaf economics spectrum' (LES) composed of these different leaf traits, which runs from quick to slow return on investments of nutrients and dry mass in leaves. The Integrated Screening Programme conducted under laboratory conditions on a more limited number of species but a wider range of traits point to the same conclusions (Grime et al. 1997).

It is recognised that many of the physiological and protective features of green leaves persist through senescence, leading to the so-called afterlife effects (Grime and Anderson 1986), whereby certain features of living organs relate to those of dead leaves, i.e. leaf litter (Cornelissen and Thompson 1997; Wardle et al. 1998; Cornelissen et al. 1999; Pérez-Harguindeguy et al. 2000). A recent meta-analysis involving 818 species from 66 decomposition experiments on 6 continents indeed showed that the degree to which inter-specific variations in living leaf structure and composition affect the decomposition rate of litter could be as large as the effect of global climatic variation (Cornwell et al. 2008). This meta-analysis showed that both SLA and LNC, two traits involved in the LES, were positively related to litter decomposition rate. Leaves with high SLA and LNC, therefore, tend to produce litter with chemical and/or 
structural properties leading to rapid decomposition. The LES, therefore, not only corresponds to features of green, living leaves, but also extends to those of leaf litter.

Among the traits involved in the LES, SLA appears as the easiest, quickest and cheapest to measure and is thus widely used to assess the position of species on the acquisition/conservation trade-off (Westoby 1998; Weiher et al. 1999; Westoby et al. 2002). Wilson et al. (1999) challenged this conclusion and proposed that leaf dry matter content (LDMC, the ratio of leaf dry mass to leaf water-saturated fresh mass) be used instead of SLA for this purpose. LDMC, which is one of the SLA components together with leaf thickness and density (Roderick et al. 1999; Garnier et al. 2001b; Vile et al. 2005), is indeed easier to measure and less prone to measurement errors than SLA since only masses have to be measured, is less variable than the latter among replicates (Wilson et al. 1999; Garnier et al. 2001a) and might be used when species from shaded habitats are involved in the comparisons (Wilson et al. 1999). Although these statements may be correct, we currently lack an evaluation comparable to that which has led to the identification of the traits involved in the LES for LDMC. Limited evidence suggest that LDMC is less tightly related to $\mathrm{PS}_{\mathrm{m}}$ and RGR than SLA at the whole-plant level (Poorter and Garnier 2007), while the comparison of three data sets where SLA, LDMC and LLS are available (Ryser and Urbas 2000; Wright 2001; Prior et al. 2003; Navas et al. 2010) shows a looser relationship between LDMC and LLS than between SLA and LLS (Fig. 5). By contrast, in the few experiments where litter decomposition has been related to SLA and LDMC, the relationship has always been found to be tighter with the latter (Fortunel et al. 2009a). This is probably because LDMC, which reflects the proportion of hard tissues in the leaves (Garnier and Laurent 1994), is the SLA component which relates best to initial litter properties controlling decomposition (cf. Kazakou et al. 2009). Therefore, if we want to capture a maximum of aspects of plant functioning from resource acquisition to resource cycling in the environment via litter decomposition, both SLA and LDMC should be measured.

Interestingly, recent broad-scale inter-specific comparisons of wood traits in trees suggest that an economics spectrum might also apply to other organs of the plant, the trunk in these particular cases (Chave et al. 2009; Weedon et al. 2009; Freschet et al. 2010).

\subsection{The height dimension}

As an overall assessment of plant stature, height is a quantitative trait which has been adopted by virtually everyone doing comparative plant ecology (Westoby et al. 2002 and references therein). The height dimension of an
Leaf life span (days, log scale)
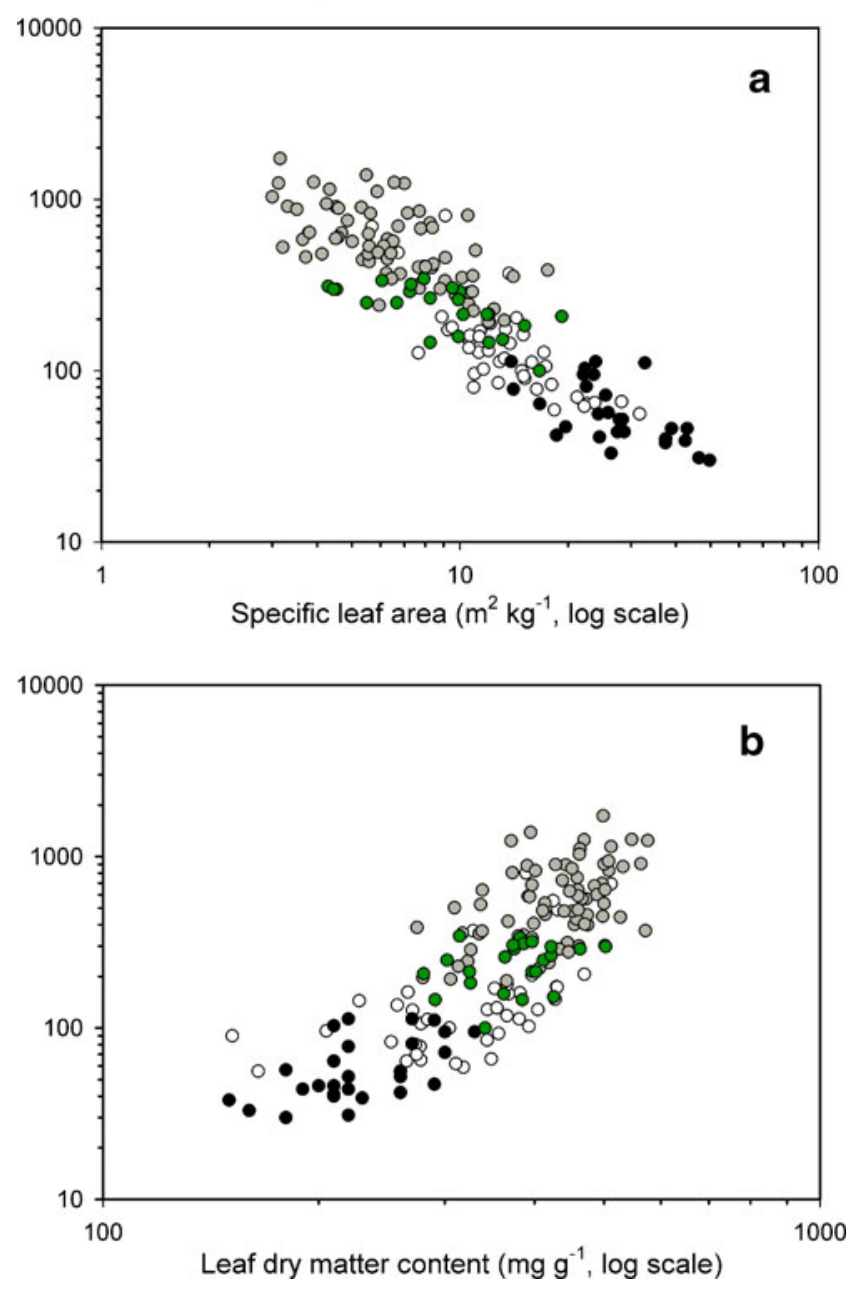

Fig. 5 Comparisons of relationships between a LLS and SLA and b LLS and LDMC. Correlation coefficient for the relationship in a $r=-0.88(P<0.001, n=165)$ and b $r=0.80(P<0.001, n=165)$. Black points data from Ryser and Urbas (2000), grey points data from Wright (2001), green points data from Prior et al. (2003), white points data from Navas et al. (2010)

individual should be considered in relation to the height of neighbours: being taller than neighbours confers competitive advantage through prior access to light and is, therefore, central to a species' carbon gain strategy (King 1990; Westoby et al. 2002). The height at which flowers and seeds are produced might also influence reproductive biology, dispersal in particular (Greene and Johnson 1989; Bazzaz et al. 2000).

Height has been shown to be the primary driver of light extinction down the canopy of plant species (Fig. 6a) (King 1990; Violle et al. 2009), explaining most of the variation in growth reduction of competing individuals (Gaudet and Keddy 1988; Violle et al. 2009). In spite of this very clear effect and its easiness of measurement, the interpretation of height attributes should be done with caution, since height is very dynamic, depending strongly on plant 
Light transmission $\left(\mathrm{J} \mathrm{cm}^{-2}\right)$

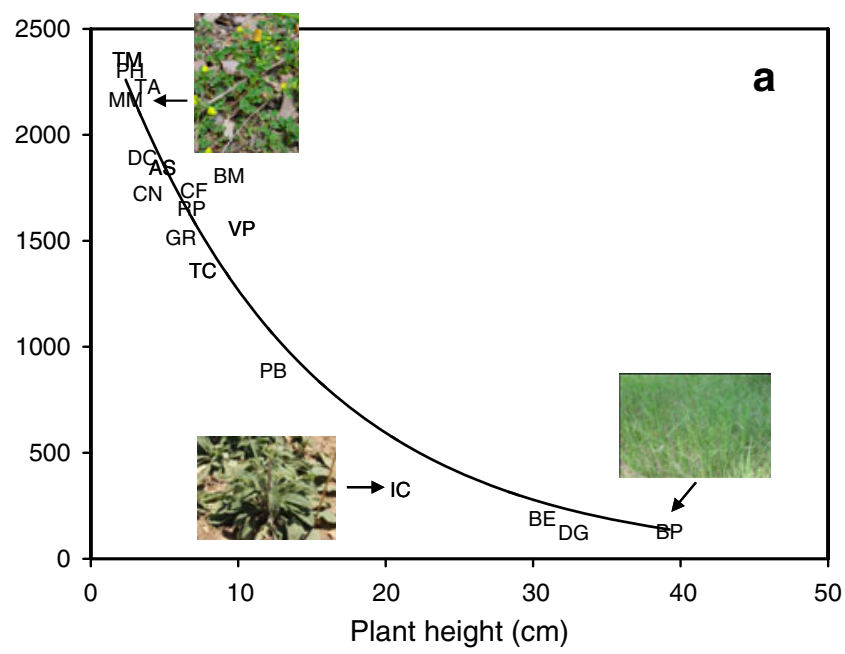

Soil transpirable water (\% of maximum)

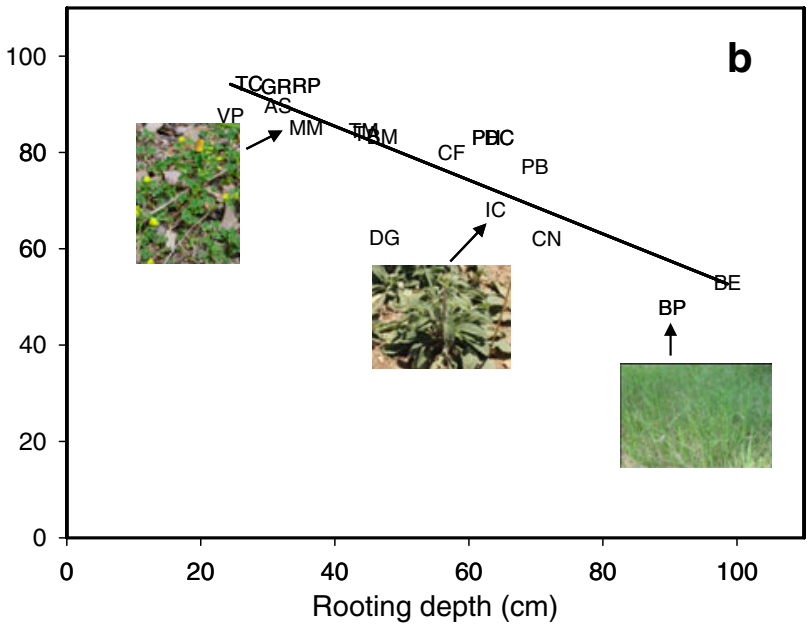

Fig. 6 a Light depletion as a function of plant height and b soil transpirable water (an index of water content) as a function of rooting depth, measured in 18 monocultures grown in an experimental garden. Species are represented by their initials to illustrate the generality of relationship: AR Arenaria serpyllifolia, BP (photograph) Brachypodium phoenicoides, $\mathrm{BE}$ Bromus erectus, $\mathrm{BM}$ Bromus madritensis, CN Calamentha nepeta, CF Crepis foetida, DG Dactylis glomerata, DC Daucus carota, GR Geranium rotundifolium, IC (photograph) Inula conyza, MM (photograph) Medicago minima, $\mathrm{PH}$ Picris hieracioides, PB Psoralea bituminosa, RP Rubia peregrine, TC Teucrium chamaedrys, TM Tordylium maximum, TA Trifolium angustifolium, VP Veronica persica. Coefficient of non-linear regression in a $r^{2}=0.93$ $(P<0.001, n=18)$; coefficient of linear regression in $\mathbf{b} r^{2}=076$ $(P<0.001, n=18)$. Redrawn from Violle et al. (2009)

ontogeny and disturbance regime in particular. This originally led Westoby (1998) to propose the use of canopy height at maturity (or potential canopy height) as the trait describing this strategy dimension.

This notion of potential canopy height is widely used for trees, for which the distinction between vegetative and reproductive heights can be ignored. This is not the case for herbaceous species, where the top of reproductive struc- tures may be substantially higher than the top of vegetative parts. It has, therefore, been argued that, in these species, vegetative and reproductive plant heights be explicitly considered as two different traits (McIntyre et al. 1999; Vile et al. 2006b; Garnier et al. 2007). McIntyre et al. (1999) even suggested that the prominence of the inflorescence above the vegetative plant body be considered a specific response trait to disturbance in grasses. In addition, vegetative plant height might sometimes be difficult to define from a morphological perspective in herbaceous species. For example, some annual grasses produce only one rapidly heading tiller, while some rosette species produce a stalk at the end of an elusive vegetative stage and some legumes with indeterminate growth produce leaves and flowers at the same time. In these cases, reproductive height at maturity is the only operational assessment of plant height. How it relates to the relative competitive ability for light still remains to be assessed, however (see discussion in Violle et al. 2009). It follows that, for broad-scale comparisons of herbaceous species differing in growth forms and habits, reproductive plant height might be the most relevant trait to measure.

Height also correlates with a number of other dimensions pertaining to plant stature. In trees, it is positively related to trunk basal area up to a certain height, with speciesdependent relationships (e.g. King 1990; Niklas 1995a, b; Wirth et al. 2004). A combination of height with basal area in equations of the form ([Basal Area $]^{2} \times$ Height) has extensively been used to assess tree above-ground biomass, with improved estimations when wood-specific gravity is taken into account (Chave et al. 2005 and references therein). Similarly, in herbaceous plants, plant height scales positively with stem diameter (Niklas 1995b) and average cross-sectional area of roots (Wahl and Ryser 2000; Hummel et al. 2007). Such increases in several plant dimensions are likely to confer higher stiffness and better anchorage abilities necessary for enlarged height growth. Tall plants also tend to be deep-rooted (e.g. Schenk and Jackson 2002; Violle et al. 2009). As soil humidity increases with soil depth during dry periods (e.g. Meinzer et al. 1999), tall plants are likely to have access to larger water sources than would smaller, shallow-rooted plants (Schenk and Jackson 2002). Whether this can improve water status during drought will depend in particular on how plant height (and rooting depth) relates to total plant leaf area and stomatal regulation of transpiration.

Finally, plant height is also an important part of a coordinated suite of life history traits including seed mass, time to reproduction, longevity and the number of seeds a plant can produce per year (Moles and Leishman 2008 and references therein). In particular, a high reproductive height enhances pollination and/or efficiency of seed dispersal in herbaceous species (Waller 1988; Verbeek and Boasson 
1995; Lortie and Aarssen 1999; Soons et al. 2004), explaining the large investment of many grassland plant species, especially rosette plants, in stalk length (Bazzaz et al. 2000). In trees, the height at which seeds are released has a positive effect on the distance at which these seeds are dispersed and is one of the parameters taken into account in most dispersal models (e.g. Greene and Johnson 1989; Kuparinen 2006).

Beyond these positive correlations, height carries several trade-offs which are not fully understood: these include the upper limit on height, the pace at which species grow upwards, the duration over which stems persist at their upper height (King 1990; Westoby et al. 2002).

\subsection{The seed size dimension}

Seed mass varies among species over a range of more than ten orders of magnitude (Harper et al. 1970; Moles et al. 2005a) and appears to be one of the least plastic components of plant structure (Harper et al. 1970). Seed mass affects virtually all aspects of plant ecology, including dispersal, seedling establishment and persistence (Harper et al. 1970; Westoby 1998; Weiher et al. 1999; Fenner and Thompson 2005).

A well-documented trade-off pertaining to seed production concerns seed mass and number. For a given carbon investment to reproduction, plants can either produce many small or few large seeds (Smith and Fretwell 1974; Shipley and Dion 1992; Leishman et al. 2000) (Fig. 7) and seed mass appears as the best easy predictor of seed output per square metre of canopy cover (Westoby 1998). These extremes, therefore, reflect two different strategies of maximising either output or competitive ability (Jakobsson and Eriksson 2000). The large output advantage of smallseeded species is actually counter-balanced later in the life cycle, mainly at the seedling stage: large seeds tend to produce large seedlings both within and among species (reviewed in Leishman et al. 2000), which have a higher probability of survival under different kinds of unfavourable environmental conditions (Jakobsson and Eriksson 2000; Leishman et al. 2000 and references therein). This includes situations where seedlings compete with established vegetation and/or other seedlings, germinate under deep shade, in the soil or under a deep litter layer (reviewed in Westoby et al. 2002). Such advantages are the consequence of large seeds having larger amount of reserves, allowing seedlings to sustain respiration for longer periods under carbon deficit (Westoby et al. 2002).

The relationships between seed mass and species dispersal ability in space and time have also been the subject of much research. Dispersal in space has been related to seed mass, in that wind-dispersed seeds tend to be light in mass and that small seeds are associated with
Number of seeds per ramet (log scale)

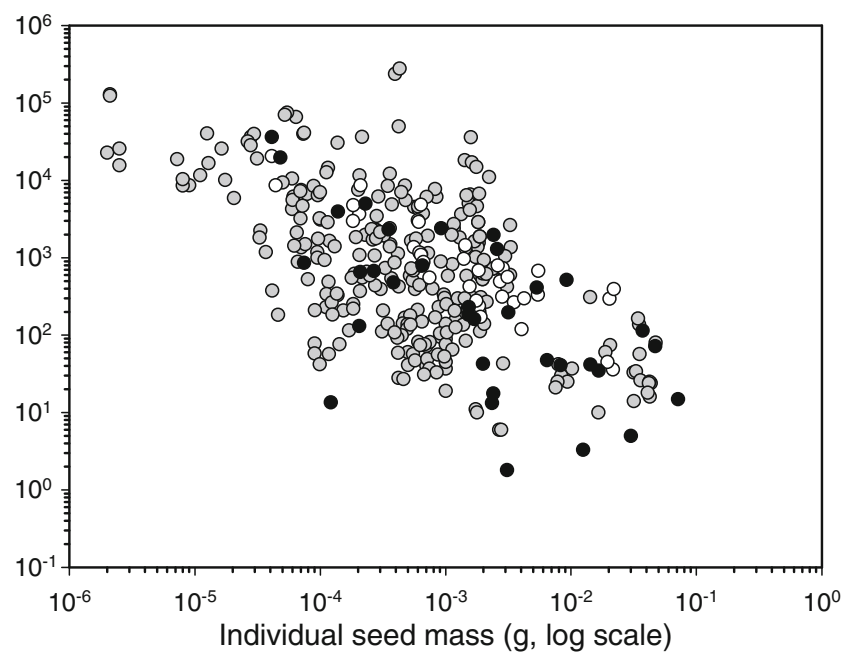

Fig. 7 Relationship between number of seeds per ramet (e.g. individual vegetative unit) and the average mass of individual seeds of herbaceous angiosperms for three data sets. Grey points data for 285 ramets representing 57 species from wetlands, roadsides, old fields, ditches and woodlands (taken from Shipley and Dion 1992); black points data for 34 species growing in Mediterranean old fields (taken from Vile et al. 2006b); white points data for 18 species from Mediterranean old fields grown in an experimental garden at two nitrogen levels (taken from Fortunel et al. 2009b). Correlation coefficient: $r=-0.61(P<0.001, n=347)$

large seed production enhancing dispersal by itself (Weiher et al. 1999). However, dispersal distances, which also depend on other attributes of the propagule and dispersal agents themselves, have not been found to be easily related to seed mass or any other plant attribute (Hughes et al. 1994). Dispersal in time can be assessed as the propagule longevity in the seed bank (Thompson et al. 1998). Thompson et al. (1993) were the first to show that a combination of seed mass and shape could be used to predict seed persistence in the soil: in the British flora, small and compact (round) seeds were found to persist longer in the seed bank than large and elongated seeds. This has subsequently been found in other European, South American and Iranian floras (references in Fenner and Thompson 2005), but not in the Australian flora (Leishman and Westoby 1998). Fenner and Thompson (2005) argued that this was due to the presence of many large, hard-seeded species in the Australian data set, which were likely to be persistent because of their physical dormancy. Whatever the case, persistence in the seed bank might well depend on seed attributes other than simply size and shape.

Finally, seed mass is connected with other traits such as growth form and plant height. On average, seed mass is higher in woody than in herbaceous species, in trees than in shrubs and in herbaceous perennials than in annuals (Moles et al. 2005a; Tautenhahn et al. 2008 and references therein). 
More generally, large species tend to produce larger seeds than small species (Rees 1997; Thompson et al. 1998; Rees and Venable 2007), and there is currently intense debate as to what evolutionary models might account for this positive relationship (Venable and Rees 2009; Westoby et al. 2009). It is beyond the scope of this paper to review the different arguments put forward, and we will simply report here some of the concluding sentences proposed by Venable and Rees (2009): 'So why do large plants have large seeds? [...] The pattern is a weak one. While very small plants never produce seeds as large as those of big seeded trees, plants of any size have seeds that vary approximately 400-650fold between species. In terms of the fitness consequences of seed size, this is a huge inter-specific range, independent of adult size'.

\subsection{Beyond a three-dimensional scheme}

The restricted number of traits discussed above should be considered as capturing a shortlist of leading, readily quantifiable dimensions of variation among species (Westoby et al. 2002). The list needs not stop here, but if reasonably wide agreement can be achieved about a few traits worth measuring consistently, then we may hope for considerable benefits from using these traits as predictors of ecological behaviour (Westoby 1999; Westoby et al. 2002). These traits could then be used to compare ecological communities on common grounds and/or literature synthesis.

It is clear, however, that the limited number of dimensions captured by such a short list of traits cannot account for all aspects of plant and vegetation functioning. For example, to understand vegetation response to disturbance (McIntyre et al. 1999; Weiher et al. 1999), land use change (Garnier et al. 2007) or water availability (Ackerly 2004), traits relevant to the particular environmental variable under investigation should be measured. But the key point is that traits describing the leading dimensions identified so far should be included, as well as absolute variables, allowing one to compare species and experiments. This was indeed the case in the four examples mentioned above in which SLA, plant height and seed mass were actually considered.

Only above-ground traits, which are relatively easily accessible, have been discussed so far. Recent studies have endeavoured to provide the same kind of information below-ground, focusing on the functions of root traits, trade-offs among them, and how they relate to aboveground traits that could then be used as proxies for belowground function (Lavorel et al. 2007 and references therein). Suites of correlated traits appear to also exist in roots and represent a trade-off between root longevity and growth rate (cf. Roumet et al. 2006; Craine 2009; Freschet et al. 2010). However, root traits are definitely not easy to measure, and a number of challenges still need to be addressed (Lavorel et al. 2007): (1) identify traits related to key root functions such as nutrient acquisition, anchoring, rhizospheric activity, decomposition rate; (2) test relationships between leaf and root traits for later use of leaf traits as potential proxies of root functions; (3) standardise root trait measurements for broad comparisons. Further leading dimensions pertaining to root functioning might well be identified in the near future, provided that root research catches up with that conducted on the other structures of the plant.

\section{A functional approach to plant community structure}

\subsection{Environmental gradients and response traits}

Plant functional traits have been intensively used to identify groups of species with similar response to a particular environmental factor (upper part of Fig. 3), defined as functional response groups (Gitay and Noble 1997; Lavorel et al. 1997). There is now a large body of data documenting how plant traits vary in relation to major environmental factors. Although most significant associations between traits and environmental factors have been obtained using a correlative approach, some of them appear robust enough among sites and vegetation types to form the basis of functional classifications for global-scale modelling (Lavorel et al. 2007; Harrison et al. 2010).

Recent reviews document which traits vary consistently along environmental gradients, thereby identifying 'response traits' (Lavorel and Garnier 2002). Leaf traits related to resource economy, including SLA, vary with nutrient availability, as do some root traits (Lavorel and Garnier 2002; Lavorel et al. 2007; Ordoñez et al. 2009). Traits describing plant phenology, leaf structure and/or root morphology vary with water availability (Niinemets 2001; Ackerly 2004; Mitchell et al. 2008). Life cycle, plant morphology and re-growth ability are involved in plant response to grazing (Diaz et al. 2007) and/or to fire (Ackerly 2004; Pausas et al. 2004; Keith et al. 2007).Traits linked to more complex environmental gradients have also been identified. For example, traits responding to change in temperature or moisture availability such as life form, leaf size, plant height and root architecture can be used to describe the response to climate (Thuiller et al. 2004; Fortunel et al. 2009a; Moles et al. 2009). Similarly, leaf traits related to resource economy, plant phenology and life form have been found to vary significantly along gradients of secondary succession (Garnier et al. 2004; Navas et al. 2010) and land use (Garnier et al. 2007; Quétier et al. 2007). The reader is referred to these various studies for more details. 
A key issue in this analysis of trait response to environmental factors is that the abundances of those species which persist in a community are usually not identical. In general, plant communities have a typical structure with a relatively small number of dominant species which account for a high proportion of the total biomass and a large number of minor species that account for a low proportion of the biomass (Whittaker 1965; Grime 1998). It has been argued that this pattern of abundance was reflecting differential adequacy between species and their environment, dominant species being better fit than less abundant species (Vile et al. 2006a; Cingolani et al. 2007). This generally results in a tighter relationship between traits and environment when species abundance is taken into account by calculating community-weighted means (CWM) of traits (see Section 4.5 and Fig. 8a) (Garnier et al. 2004; Shipley et al. 2006; Vile et al. 2006a; Cingolani et al. 2007; and see discussion in Pakeman et al. 2008).

\subsection{Assembly rules and environmental filters}

The need to identify rules governing the assembly of communities to predict which subset of the species pool found in a particular geographical region will occur in a specific habitat (first steps described in Fig. 2) was first recognised by Diamond (1975). However, rules originally searched for by description of plant or animal associations were highly contingent and failed to provide us with general principles about actual multi-species communities. More recently, assembly rules have been considered as resulting from the impact of filters imposed on a regional species pool that filter out phenotypes with non-appropriate values of response traits, whereas species with appropriate trait values survive to reproduce (Keddy 1992a; Weiher and Keddy 1999; McGill et al. 2006).

It has been hypothesised that community organisation was the result of three main filters operating at different levels (Belyea and Lancaster 1999; Lortie et al. 2004): (1) a dispersal filter, which determines the pool of potential colonists available at a particular time and place in relation to stochastic biogeographical events, storage effects and landscape structure; (2) an abiotic filter, which expresses the impacts of environmental conditions (soil $\mathrm{pH}$, humidity, temperature, etc.), resource availability and disturbance; (3) a biotic filter, pertaining to positive and negative interactions among organisms in the community. The two latter filters restrict species establishment and mediate interactions among successful colonists: individuals are filtered on the bases of their physiological tolerance to the environment and their ability to cope with organisms they interact with. Recently, new experimental and statistical procedures aiming at disentangling the relative effects of these different filters have demonstrated
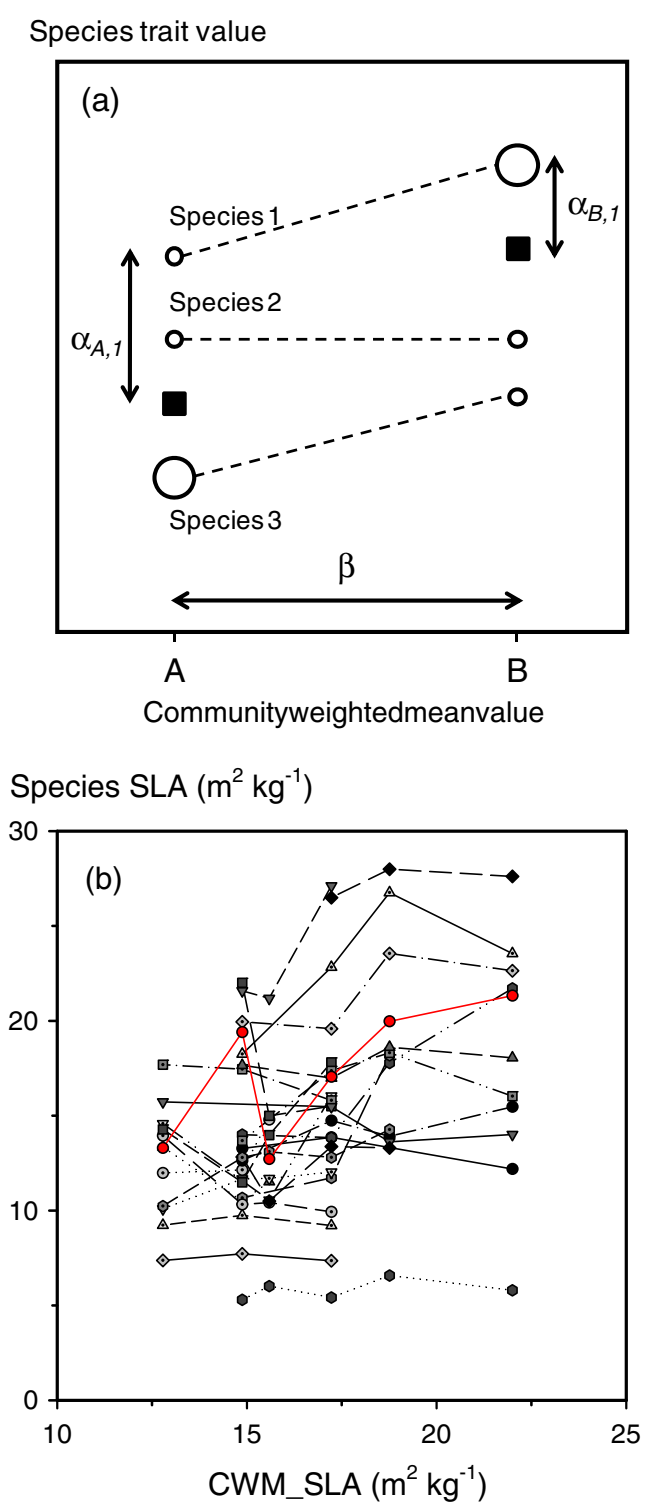

Fig. 8 Decomposition of the variation in CWM of traits into betweensite $(\beta)$ and within-site $(\alpha)$ variation. a Trait values of three hypothetical species at two different sites are shown; the size of the symbol is proportional to the abundance of the species; the black squares represent the CWM values in each community and the vertical arrows represent $\alpha$ variation for species 1 within the two sites with CWM values $\mathrm{A}$ and $\mathrm{B}\left(\alpha_{A}, 1\right.$ and $\left.\alpha_{B}, 1\right)$, while horizontal arrow shows the variation of CWM values ( $\beta$ trait variation) between the two sites (derived from Ackerly and Cornwell 2007; Shipley 2010); b Actual decomposition along a nutrient availability gradient in Mediterranean rangelands, where values on the $\mathrm{X}$-axis show the variation of community weighted means of specific leaf area (CWM_SLA) on 6 points along the gradient ( $\beta$ trait variation). The Y-axis shows the $\alpha$ trait variation for a number of species (each symbol and line represent a different species) present in the different situations along the gradient (the grass Bromus erectus is the only species present in the 6 situations and is shown in red). Data taken from Fayolle (2008)

a major impact of habitat filtering over stochastic events especially due to dispersal (Gilbert and Lechowicz 2004; Cornwell et al. 2006): although the taxonomic identity of 
co-occurring species was found to depend on historical contingency, species with similar trait values tended to cooccur more often than expected by chance.

\subsection{Assembly rules and trait distribution within communities}

Identifying how community assembly processes shape the distributions of trait values within and among communities is a major goal of community ecology (Weiher and Keddy 1995; Weiher and Keddy 1999; McGill et al. 2006). Trait distribution at a site is said to be convergent (respectively divergent) when the range of trait values is narrower (respectively larger) than expected by chance. Habitat filtering generally leads to convergence of traits within a community (cf. Fig. 2) due to common adaptation to the physical environment (Cornwell and Ackerly 2009; de Bello et al. 2009). However, convergence is generally more stringent in vegetative traits responding to resource levels than in regenerative ones responding to disturbance (Grime 2006) (cf. the two hypotheses shown in Fig. 2). By contrast, niche differentiation that limits interactions among similar plants - the limiting similarity principle-leads to trait divergence (Stubbs and Wilson 2004; Wilson 2007; Cornwell and Ackerly 2009). Therefore, the extent to which trait values tend to converge or diverge within communities depends on the balance between processes related to habitat constraints and those leading to limiting similarity between individuals. As a consequence, attribute convergence varies with spatial scale: traits involved in interactions with other plants such as those describing resource use are generally less convergent at the neighbourhood scale than at the habitat scale (McKane et al. 2002; Stubbs and Wilson 2004; Cavender-Bares et al. 2009). Convergence of traits may also vary with time: divergence is often promoted in the regenerative phase (Fukami et al. 2005; Kraft et al. 2008) as a response to the unpredictability of disturbance events governing recruitment (Grime 2006), whereas traits used to characterise the established phase of the life cycle tend to converge as a result of the non-random mortality of juveniles.

Changes in trait distribution among communities are not only due to species replacement: the intra-specific variability of traits due to phenotypic plasticity or ecotypic variation is far from being negligible (cf. Fig. 8b) and may explain a substantial part of attribute variations along regional gradients (Cornwell and Ackerly 2009). The relative importance of inter- vs. intra-specific variability of attributes is likely to depend on the situation under study because of large differences in intra-specific variability among traits along different types of gradients (Garnier et al. 2001a; Roche et al. 2004). Characterising this relative importance on trait distribution is critical in the context of global change: organisms might first respond to shifts in environmental conditions through plasticity of individual species, while species replacement and/or genetic shifts within the species might then follow (Ackerly 2003), with larger impact on functional characteristics of communities.

Recognising the importance of intra-specific variation among sites, Ackerly and Cornwell (2007) proposed to decompose species mean trait value into two components: beta trait value refers to species mean position along an environmental gradient (i.e. a measure of niche position) and alpha trait value is the difference between a species trait value and the weighted mean of co-occurring taxa within a community (Fig. 8). This partitioning of trait values builds on alpha and beta niche of species (Pickett and Bazzaz 1978; Ackerly et al. 2006): the alpha niche refers to attributes that differentiate a species from cooccurring taxa and, therefore, may contribute to nonneutral maintenance of species diversity within a community, whereas the beta niche refers to species distribution across habitat or geographic gradients. Beta trait values have generally lower divergence than expected at random (cf. example of Mediterranean rangelands along a nutrient gradient, Fig. 8b), an observation consistent with the hypothesis of trait convergence due to habitat filtering. By contrast, alpha trait values are generally highly variable, which might be interpreted as a limiting similarity effect (Cornwell and Ackerly 2009; de Bello et al. 2009).

\subsection{Phylogeny, traits and community assembly}

A highly debated issue is to understand whether trait convergence as discussed above is related to the position of species in the phylogeny (Webb et al. 2002). A frequent assumption is that closely related species are more similar in terms of environmental requirements than more distantly related species (niche conservatism). According to this hypothesis, a clustered phylogenetic structure of communities is expected when traits converge because of habitat filtering: species should be more often phylogenetically related than expected at random. However, at the neighbourhood scale where trait divergence is due to processes limiting similarity between plants, the same hypothesis leads to the prediction of an over-dispersed phylogenetic structure: interacting species should be less often phylogenetically related than expected at random. By contrast, habitat filtering might lead to an over-dispersed phylogenetic structure if traits important for habitat specialisation are labile and close relative species specialise for different niches.

Understanding the influence of phylogeny on the functional structure of communities has been the topic of 
numerous experimental studies (for a recent review, see Cavender-Bares et al. 2009). A first conclusion is that phylogenetic conservatism differs among traits; for example, seed mass is a highly conserved trait among American Quercus species, whereas plant height is not (CavenderBares et al. 2006). A second conclusion is that the phylogenetic structure of communities is generally nonrandom at multiple spatial and taxonomic scales, revealing a major influence of habitat filtering and competitive interactions on species distribution. Unravelling the impacts of phylogenies on community assembly is still in its infancy and is a whole research field under development. A central issue will be to detect the importance of the phylogenetic signals on traits (see example of the phylogeny of LMA in Fig. 3), which will be made possible by the increasing availability of phylogenetic data, computing power and informatics tools (Cavender-Bares et al. 2009). Possible applications include the prediction of ecosystem processes from the phylogenetic structure of communities, provided that effect traits as defined above are phylogenetically conserved (Cadotte et al. 2009).

\subsection{The functional structure of communities}

The functional structure of a community has been originally described by the diversity in functional types based on differences in life form, plant morphology or resource acquisition types (e.g. N-fixing or non-fixing species, $\mathrm{C} 4$ or $\mathrm{C} 3$ photosynthetic pathways, etc.) (Lavorel et al. 1997). Because of limitations of methods based on discrete and subjective classifications, the functional diversity (FD) of communities is currently defined as the value, range and relative abundance of traits found in a given community (Díaz et al. 2007a).

This functional structure can be described through two components, value and range of traits (cf. Fig. 3), corresponding to two types of quantitative variables. The first ones allow one to estimate the average value of traits in the communities and can be written as:

$\mathrm{CFP}=\sum_{i=1}^{n} p_{i} \times$ trait $_{i}$

where CFP represents the functional parameter of the community (Violle et al. 2007b), $p_{i}$ and trait ${ }_{i}$ are, respectively, a weighting factor and the trait value for species $i$ and $n$ is the total number of species in the community. When only presence/absence data for species are available, all $p_{i}$ are fixed at the same value $(1 / n)$ and the calculated CFP are unweighted averages; when species abundances are known, a common procedure is to use the relative abundance of species as $p_{i}$ values, thereby calculating CWM (Garnier et al. 2004; for different weighting procedures, see also Hodgson et al. 2005). CWM represents the most probable attribute that a species taken at random in the community will display. This calculation is based on the mass-ratio hypothesis (Grime 1998, and detailed in Section 5.1), which proposes that the controls on function by species are proportional to their abundance. CWM is a robust index showing low susceptibility to experimental procedures used to evaluate species relative abundance and trait values (Lavorel et al. 2008).

The second type of variables aims at describing the functional dissimilarity among the species present in the communities. Numerous indices have been proposed to do so (reviewed in Petchey and Gaston 2006). Some are based on the sum of (functional attribute diversity: Walker et al. 1999) or average (quadratic entropy: Lepš et al. 2006) functional distances between species pairs in a multivariate functional trait space, distances between species along a hierarchical classification (FD: Petchey et al. 2004) or on the distribution of abundances along functional trait axes ( $\mathrm{FD}_{\text {var }}$ : Mason et al. 2003). More recently, indices of phylogenetic diversity that specifically take into account species abundance in the community were proposed as surrogate of FD for traits supposed to be highly conserved through phylogeny (Cadotte et al. 2010).

The design and use of these indices are currently highly debated. A critical point is that they must meet several criteria to be of general use: they must be designed to deal with several traits if necessary, take into account species abundance and measure all facets of FD. First, the question of how many and which traits to use is crucial to get as complete an identification of FD as possible: traits must be relevant to account for mechanisms of species coexistence as well as effects of species on ecosystem functioning (see Section 5.1). Increasing the number of traits should thus make the identification of FD clearer; however, this can induce trivial relationships with species richness that should be avoided. These arguments led Lepš et al. (2006) to suggest that traits that represent different ecological strategies or allow one to assess ad hoc response to environmental factors are the best candidates. By contrast, quantitative methods for selecting traits without a priori arguments are currently being developed (BernhardtRomermann et al. 2008; Sonnier et al., submitted). Second, the effect of each species in the calculation of indices has to be weighted according to abundance in order to reflect species contribution to ecosystem functioning, as stressed above and in Section 5.1. This criterion, whose importance remains to be established in the case of community dynamics, is not fulfilled for most indices based on functional distances between species pairs. Third, FD is a rather complex idea that can be partitioned into three components: functional richness, defined as the volume of the functional space occupied by the species in the community; functional evenness, defined as the regularity of the distribution of abundance in this volume; functional 
divergence (FDvg, hereafter), represented by the divergence in the distribution of abundance in this volume (Fig. 9). Initially calculated with single-trait indices (Mason et al. 2005), new procedures using several traits have been recently proposed (Villeger et al. 2008). Among these components, FDvg appears of particular interest to characterise the FD of communities by revealing the complementary (high FDvg) or similarity (low FDvg) in species traits within a community, corresponding to the divergence vs. convergence issue as discussed in Section 4.4.

\section{Traits and ecosystem properties}

Chapin et al. (2002) recognise that EP are controlled by two broad categories of factors: (1) independent controlling variables (state factors), which are climate, parent rock material, topography, potential biota and time, and (2) interactive controls, which are factors that both control and are controlled by EP: resources, modulators (temperature, $\mathrm{pH}$, etc.), disturbance, biotic community and human activities. The occurrence of different controls on EP at large scales is illustrated in Fig. 10, showing the relationships between net primary productivity (NPP) of different biomes and either annual rainfall or mean height of vegetation. For a detailed account of these different controls
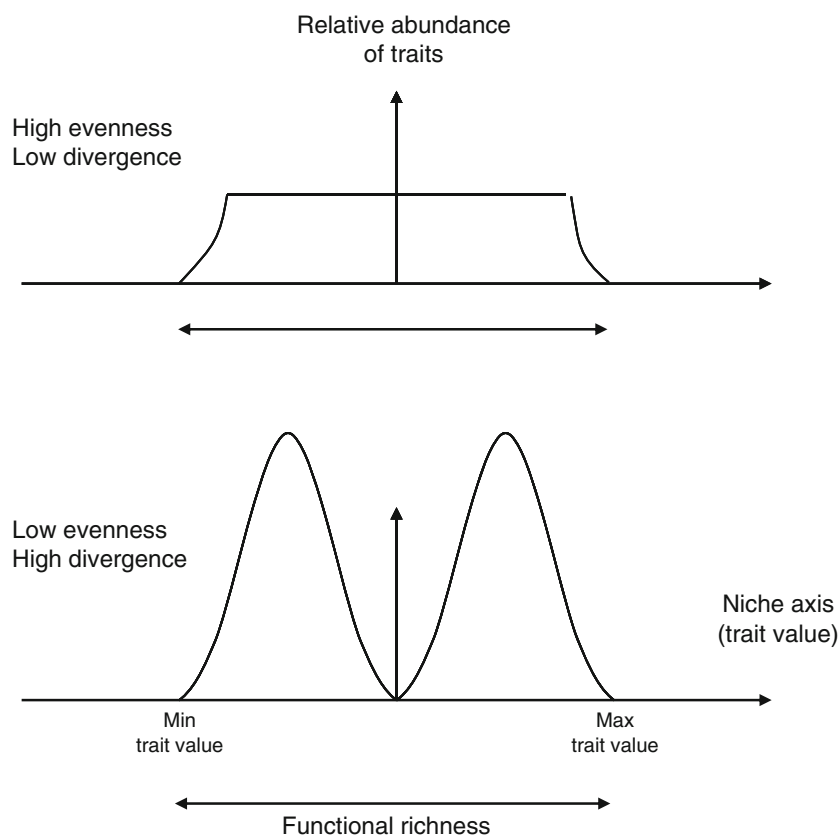

Fig. 9 Components of FD. Functional richness corresponds to the portion of niche axis represented by the range of trait values found in the community. Functional evenness and divergence represent, respectively, the regularity and divergence of distribution of traits across the niche axis. Here, we represent two theoretical cases representing contrasted patterns in functional evenness and divergence for a same functional richness and average trait value on various EP, the reader is referred to, e.g. Schulze and Zwölfer (1987), Aber and Mellilo (2001) and Chapin et al. (2002). Here, we will focus on studies which have explicitly investigated the controls that plants, as major players in the biotic component, might exert on EP, alone or in combination with various other factors.

Awareness that plant communities have substantial impacts on EP has long been recognised (reviewed in Vitousek and Hooper 1993; Grime 2001; Chapin et al. 2002; Wardle 2002; Eviner and Chapin 2003). The issue of whether and why more species and/or predefined functional groups have significant effects on the functioning of ecosystems has been the subject of a lively debate over the past two decades (for recent syntheses, see, e.g. Loreau et al. 2001; Hooper et al. 2005; Balvanera et al. 2006; Cardinale et al. 2006; Cardinale et al. 2007; Naeem et al. 2009), and there is now a growing consensus that EP depends more on the functional characteristics of species than on their number (Chapin 1993; Grime 1997; Chapin et al. 2000; Díaz and Cabido 2001; Lavorel and Garnier 2002; Díaz et al. 2007a). As discussed in Section 4.5, these functional characteristics translate into two components of community FD, value and range of traits. These components can be theoretically linked to two broad hypotheses concerning the relation between diversity and EP: the selection mechanism (i.e. the selection of the dominant species: Grime 1998) and the niche complementarity effect (Petchey and Gaston 2006), respectively.

Díaz et al. (2007b) proposed a framework to assess the relative importance of abiotic and biotic controls on EP and the services they can deliver to humans, which takes into account these two components of FD. In this framework, the effects of abiotic factors are tested first, followed by those of CWM and FD; finally, potential effects of particular species and/or species groups not accounted by FD metrics are considered. In the remaining part of this section, we will, therefore, focus on studies examining the impact of FD components on EP, thereby addressing the question of how organisms and communities affect ecosystem functioning.

5.1 The biomass ratio hypothesis: community-level weighted means of traits

The selection effect forms the basis of the 'biomass ratio hypothesis' (BRH: Grime 1998), which states that particular traits of locally abundant species will determine the rate and magnitude of instantaneous ecosystem processes. Such traits have been called 'effect traits' (Díaz and Cabido 2001; Lavorel and Garnier 2002; cf. Fig. 3). According to the BRH, EP therefore depend on CWM of effect traits (Garnier et al. 2004; Díaz et al. 2007a; Violle et al. 2007b). An increasing number of studies show that this hypothesis 
Fig. 10 Examples of potential abiotic and biotic controls on ANPP of terrestrial ecosystems. Relationships between ANPP and a annual precipitation (redrawn from Gower 2002) and b average height of the vegetation (data taken from Saugier et al. 2001) for different biomes. Note that classification of biomes and ANPP values for a given biome might differ between the two studies in a $B O D B L$ boreal deciduous broadleaved, $B O D N L$ boreal deciduous needle-leaved, $B O E N L$ boreal evergreen needle-leaved, DESRT deserts, TEMGS temperate grasslands, TROGS tropical grasslands, TEDBL temperate deciduous broadleaved, TEEBL temperate evergreen broadleaved, TEENL temperate evergreen needle-leaved, TRDBL tropical deciduous broadleaved, TREBL tropical evergreen broadleaved, TUNDR tundra, $W D L N D$ woodlands; in b BORFT boreal forests, CROPS crops, DESRT deserts, MEDSH Mediterranean shrublands, TEMFT temperate forests, TEMGS temperate grasslands, TROFT tropical forests, TROGS tropical savannas and grasslands, TUNDR tundra. Correlation coefficient in a $r=0.90(P<0.001, n=13)$ and in $\mathbf{b} r=0.91(P<0.001$, $n=8)$

holds for some key biogeochemical processes such as primary productivity, components of the water balance, leaf digestibility and litter decomposition.

\subsubsection{Components of primary productivity}

Several traits related to plant growth and/or to the LES described above have been shown to affect ecosystem NPP or some of its components. Early literature surveys, which did not take species abundance into account, have shown positive associations between whole-plant RGR averaged across species and ecosystem above-ground net primary productivity (ANPP) across biomes (Chapin 1993). Building on Chapin's work (1993), a formal relationship between species traits and NPP has been proposed by Lavorel and Garnier (2002), which formalises the BRH as applied to productivity of ecosystems:

$\mathrm{NPP}=\frac{\sum_{i=1}^{n} N_{i} \times \mathrm{Mo}_{i} \times\left(e^{\mathrm{RGR}_{i} \times\left(t_{\mathrm{f}}-t_{0}\right)_{i}}-1\right)}{\Delta T}$

where $n$ is the total number of species in the community, $N_{i}$ is the number of individuals of species $i$ per unit ground area, $\mathrm{Mo}_{i}$ is the initial average biomass of individuals of species $i, \mathrm{RGR}_{i}$ and $\left(t_{\mathrm{f}}-t_{0}\right)_{i}$ are, respectively, the RGR and period of active growth of species $i$ and $\Delta T$ is the period over which NPP is assessed. Due to the difficulty to access the underground compartment, to date, most tests of Eq. 2 have been conducted taking only above-ground plant parts into account.

Since realised RGR is particularly difficult to assess in the field, this relationship has been tested using either RGR data measured in the lab $\left(\mathrm{RGR}_{\max }\right)$ or independent measurements of traits involved in the LES and/or assumed to be related to RGR (see Section 3.1). Leoni et al. (2009) report that inter-specific differences in $\mathrm{RGR}_{\max }$ measured under controlled conditions on dominant species of grazed and ungrazed plots of Uruguayan grasslands tend to scale
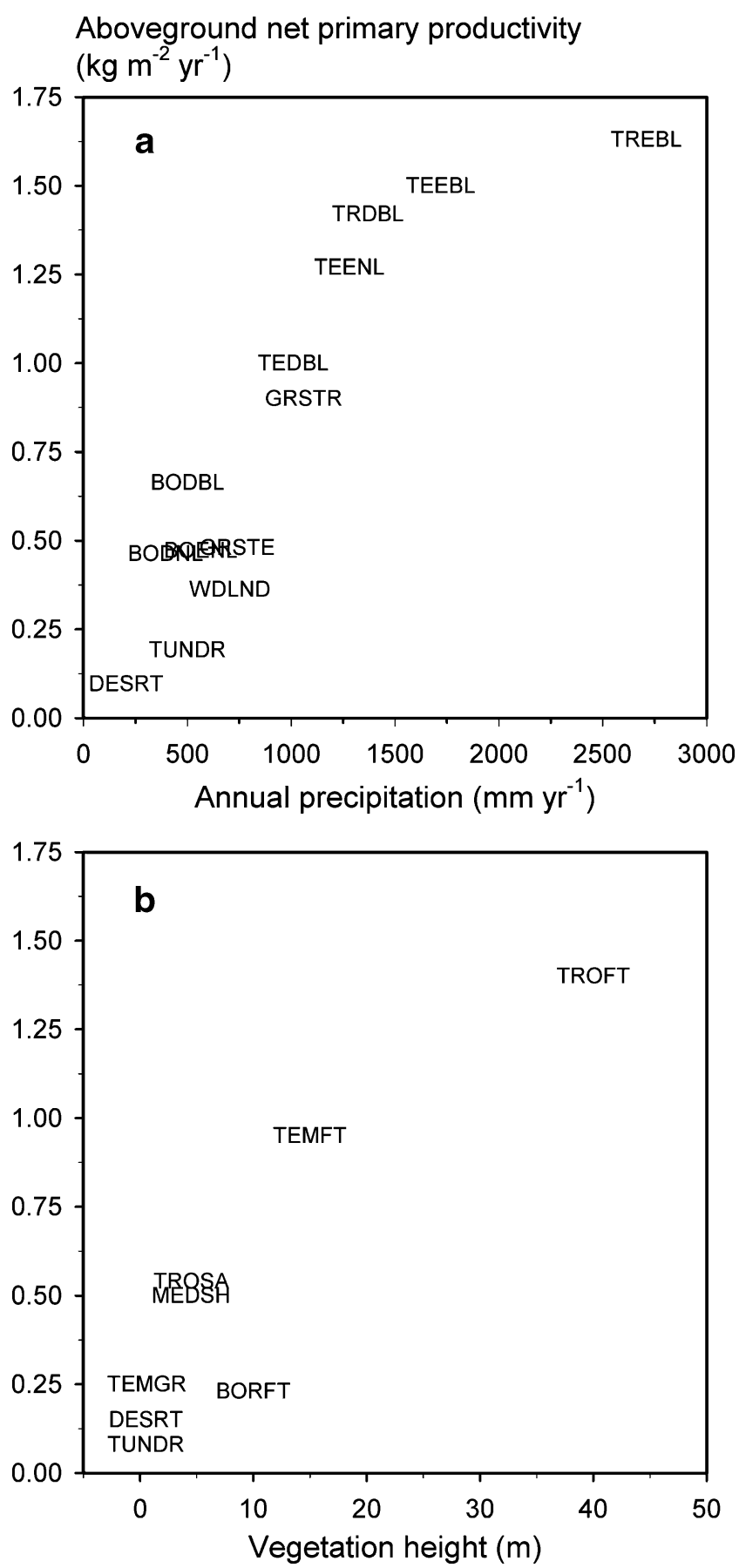

up with above-ground NPP (ANPP) measured in these plots (Altesor et al. 2005). This suggests that species ranking for $\mathrm{RGR}_{\max }$ and realised RGR remains comparable in spite of the complex differences in ontogeny, plant-environment and plant-plant interactions involved in the comparison between laboratory and field-grown plants (see discussion in Vile et al. 2006a). Different relationships were found between the CWM of various leaf traits and ANPP: ANPP was found to be related to CWM_leaf angle in Australian grasslands (Mokany et al. 2008), to CWM_leaf area in subalpine grasslands in the French Alps (Gross et al. 2008) 
and to a combination of CWM LLDMC and traits of roots and rhizomes in mesocosms of mountain grasslands of Central France (Klumpp and Soussana 2009).

In studies conducted on herbaceous ecosystems where maximum above-ground standing biomass $\left(\mathrm{AGB}_{\text {mass }}\right)$ was used as an estimate of ANPP (for discussion, see Scurlock et al. 2002), CWM_leaf area was positively related to $A_{G B}$ mass (Thompson et al. 2005; Mokany et al. 2008), while Garnier et al. (2004) found weak negative relationships between $\mathrm{AGB}_{\text {mass }}$ and CWM_SLA and CWM_LDMC and Díaz et al. (2007a) did not find any significant relationship between $\mathrm{AGB}_{\text {mass }}$ and any CWM value.

ANPP is a ground area-based variable (expressed in, e.g. grammes per square metre per day), and in Eq. 1, traits are weighted by the absolute biomass of species in the community $\left(N_{i} \times \mathrm{Mo}_{i}\right)$. This means that ANPP depends on the initial standing biomass of the whole community (see also Section 5.4) as much as on species traits. To account for this mass effect and assess more directly the role of traits as components of ecosystem productivity, Reich et al. (1992, 1997) calculated the ANPP/live canopy dry mass ratio ('ecosystem production efficiency'), while Garnier et al. (2004) built on Eq. 2 to devise a 'specific net ecosystem productivity' as:

$\mathrm{SNPP}=\frac{\log _{e}\left(\sum_{i=1}^{n} p_{i} \times e^{\mathrm{RGR}_{i} \times\left(t_{\mathrm{f}}-t_{0}\right)_{i}}\right)}{\Delta T}$

where $p_{i}$ is the initial proportion of species $i$ in the community, instead of its biomass. Ecosystem production efficiency and SNPP are both in units of grammes per gramme of green biomass per unit time and can be viewed as the RGR of the whole community. In the survey conducted by Reich et al. (1992), ecosystem production efficiency (above-ground) was found to be positively related to SLA and negatively related to LLS in forest stands. Testing Eq. 3 in a successional sere of Southern France, Garnier et al. (2004) found tight relationships between both CWM _ SLA and CWM LLNC and aboveground SNPP (see also Klumpp and Soussana 2009). Interestingly, working in the same successional sere, Vile et al. (2006a) found a positive relationship between above-

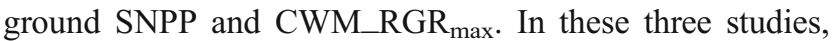
traits involved in the LES were thus shown to have a significant impact on ecosystem productivity.

Contrasting with these results in support of the BRH, Díaz et al. (2007a) found that ANPP and above-ground SNPP were both unrelated to any CWM in French subalpine grasslands, but were dependent on an index of nitrogen limitation. Over a much broader spatial scale, a study of 60 plots spread across the Amazonian forest from the Pacific to the Atlantic coasts and covering a 4,000-km range from north to south showed that coarse wood production was unrelated to CWM of maximum height and wood density and was primarily driven by environmental factors, which were not explicitly identified (Baker et al. 2009).

Clearly, the impacts of abiotic factors vs. those of the functional structure of the community on components of ecosystem NPP requires further testing on a wide range of situations.

\subsubsection{Decomposition and accumulation of litter}

Given the close coupling between SNPP and/or ecosystem production efficiency and litter decomposition across ecosystems (e.g. Cebrián and Duarte 1995; Chapin et al. 2002), the BRH is likely to apply for the process of decomposition as well, with traits involved in the LES. There is still some debate as to which characteristics of the litter have an effect of decomposition (see reviews in, e.g. Aerts 1997; Aerts and Chapin 2000; Chapin et al. 2002; Wardle 2002) and which traits of living leaves best reflects the quality of the litter (see Section 3.1). Although the BRH is, therefore, likely to apply for decomposition as well, an actual formalism comparable to that proposed above for SNPP is not straightforward. Whatever the form of the relationship, empirical tests in several situations have shown that CWM of traits involved in the LES tend to scale with community-level decomposition rates (Garnier et al. 2004; Cortez et al. 2007; Quested et al. 2007; Quétier et al. 2007; Fortunel et al. 2009a). As found at the species level, CWM LDMC correlates better with decomposition rates than either CWM_SLA (Garnier et al. 2004; Quested et al. 2007; Fortunel et al. 2009a) or CWM_leaf nutrient concentrations (Garnier et al. 2004; Fortunel et al. 2009a; but see Díaz et al. 2007b). In a broadscale study across 11 European sites, CWM LDMC was the characteristic of living leaves best related to the lignin to nitrogen ratio of the initial litter, the latter explaining $44 \%$ of the variance in litter decomposition rate (Fortunel et al. 2009a; see also Díaz et al. 2007b).

Since traits have a role both on the production and decomposition rates, we also expect effects on litter accumulation. CWM_LDMC was positively related to above-ground total dead matter in Australian grasslands (Mokany et al. 2008) and across 11 European sites (Garnier et al. 2007), while Díaz et al. (2007a) found that a multiple regression involving CWM of vegetative plant height, LNC and leaf tensile strength accounted for $75 \%$ of the variance in above-ground total dead matter.

\subsubsection{Soil water content}

At any given time, the soil water content of a particular soil depends on the balance between rainfall, actual evapotranspiration from the plant cover, surface runoff and percolation through the soil (Larcher 2003). For the sake of simplicity 
and because we have no information as to how species influence the two latter processes, these will not be considered in the following. Since actual evapotranspiration during a time interval $\Delta t$ is the sum of evaporation and water uptake from the whole cover, a simplified soil water balance model can be written as (cf., e.g. Boulant et al. 2008):

$S_{t+1}=\min \left[S_{t}+R_{\Delta t}-E_{\Delta t}-U_{\Delta t}, \mathrm{FC}\right]$

where $S_{t+1}$ and $S_{t}$ are soil water content at time $t+1$ and $t$, respectively, $R_{\Delta t}, E_{\Delta t}$ and $U_{\Delta t}$ are rainfall, evaporation from the whole cover and water uptake by plants between $t+1$ and $t(\Delta t)$, respectively, and FC is the soil field capacity (the soil water content at saturation after the gravitational water has percolated). According to Eq. 4, the decrease in soil water content after rainfall events, therefore, depends on $E_{\Delta t}$ and $U_{\Delta t}$ (see also Eviner and Chapin 2003). $E_{\Delta t}$ depends primarily on the availability of energy at the ground surface, except after rainfall when water intercepted by the canopy evaporates (cf. Schulze et al. 2005). It is inversely related to the leaf area index of the vegetation (Schulze et al. 1995) and to litter accumulation (Eviner and Chapin 2003). As traits related to plant growth and litter accumulation have been discussed in Section 5.1.2., we hereafter focus on the modulation of water uptake $\left(U_{\Delta t}\right)$ by plant traits.

Since root distribution and maximum rooting depth of the different species as well as soil properties vary with soil depth (Schwinning and Ehleringer 2001 and references therein), water uptake over the entire soil profile can be conveniently subdivided into uptake from different discrete layers. Water uptake from soil layer $i$ by species $j$ during a short time interval $d t\left(U_{d t(i, j)}\right)$ over which all variables may be considered constant follows Darcy's law and can be written (cf. Schwinning and Ehleringer 2001; Larcher 2003):

$U_{d t(i, j)}=M_{\text {root }(i, j)} \times \mathrm{SRA}_{i, j} \times k_{i, j} \times\left(\Psi_{\text {soil }, i}-\Psi_{j}\right)$

where $M_{\operatorname{root}(i, j)}, \mathrm{SRA}_{i, j}$ and $k_{i, j}$ are, respectively, the biomass of roots, the specific root area (SRA, the ratio of root area to root dry mass) and the root area-based hydraulic conductance to water transport of species $j$ in layer $i$, while $\Psi_{\text {soil }, i}$ is the bulk soil water potential in layer $i$ and $\Psi_{j}$ is the water potential of species $j$. If we assume additivity of the process among species, the decrease in soil water content over the entire soil profile can be written as:

$$
U_{d t}=\sum_{i=1}^{m} \sum_{j=1}^{n}\left[M_{\mathrm{root}(i, j)} \times \mathrm{SRA}_{i, j} \times k_{i, j} \times\left(\Psi_{\mathrm{soil}, i}-\Psi_{j}\right)\right]
$$

where $n$ is the number of species in the community and $m$ is the number of soil layers considered. Assuming that roots have a cylindrical shape, SRA can be written as:

$\mathrm{SRA}=\frac{\mathrm{RA}_{\text {root }}}{M_{\text {root }}}=\frac{L_{\text {root }} \times \pi \times d_{\text {root }}}{M_{\text {root }}}$

where $\mathrm{RA}_{\text {root}}, L_{\text {root }}$ and $d_{\text {root }}$ are the root area, the root length and the average root diameter, respectively. Combining Eqs. 5 and 6 leads to:

$U_{d t}=\sum_{i=1}^{m} \sum_{j=1}^{n}\left[L_{\mathrm{root}(i, j)} \times \pi \times d_{\mathrm{root}(i, j)} \times k_{i, j} \times\left(\Psi_{\mathrm{soil}, i}-\Psi_{j}\right)\right]$

Equations 6 and 8 show that rooting depth and root distribution of the different species in the different soil layers will have impacts on the water content of these layers. It also shows that soil-plant hydraulic properties and plant water potential might affect soil water content, beyond the effects of biomass and/or length (Eviner and Chapin 2003).

To our knowledge, Eqs. 6 and 8 have not been tested directly in complex communities, but some studies have assessed the effects of individual traits appearing in either of these on soil water content. Working in alpine grasslands, Gross et al. (2008) have found a significant effect of CWM $L_{\text {root }}$ on the water content of the upper $15 \mathrm{~cm}$ soil layer, while in Australian grasslands, Mokany et al. (2008) found a strong negative effect of CWM_SRA on the water content of the entire soil profile averaged over the growing season.

Recognising that whole-plant water uptake and transpiration are tightly coupled (cf. Schwinning and Ehleringer 2001; Larcher 2003), we also expect traits controlling water fluxes from leaves to have an impact on soil water content. This is the case not only for water potential (Eqs. 6 and 8), but also for stomatal conductance, whose sensitivity to air water vapour deficit is known to vary among species (Oren et al. 1999).

Finally, the time dependence of water uptake should also be considered, which corresponds to the integration of Eqs. 6 and 8 over time. In particular, changes in root biomass and/or length in relation to the phenology of the different species which compose the communities will have impacts on soil water content (Eviner and Chapin 2003). For example, a species which completes its life cycle during spring will have little effect on soil water content during summer, unless no rainfall event occurs (Schwinning and Ehleringer 2001; Gross et al. 2008).

\subsubsection{Other components of biogeochemical cycles}

Numerous other components of biogeochemical cycles are likely to be affected by plant traits (reviewed in Wardle 
2002; Eviner and Chapin 2003). Among those, soil carbon sequestration has recently received increased attention (de Deyn et al. 2008; Klumpp and Soussana 2009). By contrast with the properties discussed so far, a number of intermediate, complex steps have to be taken into account to understand the links between plant traits and soil C. Carbon sequestration in soils represents the balance between carbon inputs in and outputs from the soil, and many traits potentially affect these different fluxes, as well as potential species interactions (Fig. 11). Traits pertaining to plant growth rate, litter production and quality as discussed above play a substantial role in this respect.

Beyond the qualitative identification of traits affecting soil C sequestration (Eviner and Chapin 2003; de Deyn et al. 2008), Klumpp and Soussana (2009) assessed quantitatively the relative impacts of various plant traits on belowground net carbon storage (BNCS) and top soil organic carbon content (SOC) of semi-natural grasslands subjected to different grazing regimes. They found that both BNCS and SOC were negatively related to CWM_specific root length (SRL, the ratio of root length to root mass), while BNCS was positively related to CWM_root diameter. Generally, low SRL is associated with thick, dense roots with low nitrogen and high lignin concentrations (ref. in Lavorel et al. 2007), which are likely to produce slowly decomposing litter (Hobbie et al. 2010), ultimately leading to SOC stabilisation (Fig. 11). Similarly, total soil carbon content was found to be negatively related to CWM_SLA and CWM LLNC and positively to CWM LDDC in a Mediterranean old field succession (Garnier et al. 2004). As discussed above, these traits lead to slow decomposition rate of leaves (Cortez et al. 2007; Quested et al. 2007) and accumulation of litter (Garnier et al. 2007), two variables affecting the rate of carbon input in soils.

\subsection{Complementarity among species: incorporating functional divergence}

So far, only few studies have examined the impacts of FDvg on EP, either independently or in combination with CWM and abiotic effects. These were all conducted in perennial herbaceous communities, either from Europe (Thompson et al. 2005; Díaz et al. 2007b; Klumpp and Soussana 2009; Schumacher and Roscher 2009) or Australia (Mokany et al. 2008). A synthesis is currently difficult to conduct for at least two reasons. First, the restricted number of studies available for a particular EP limits our potential to generalise safely. Second, as discussed in Schumacher and Roscher (2009), the outcomes of the analyses strongly depend on the way the different variables are considered in the stepwise procedures. In particular, conclusions appear highly sensitive to the fact that variables are treated independently rather than in combination with the others and whether the selection procedure is based on individual correlations as proposed by Díaz et al. (2007b) or all variables are treated in combination in a global analysis as suggested by Schumacher and Roscher (2009). Another issue pertains to whether traits are given equal weight in the analyses (Schumacher and Roscher 2009).

A striking example is given by the study conducted by Schumacher and Roscher (2009) in semi-natural grasslands of Germany. This study showed that, when a stepwise procedure that did not place any constraint on the selection of variables introduced in the multiple regression was used, $\mathrm{AGB}_{\text {mass }}$ was best explained by a combination of total soil
Fig. 11 Potential plant trait composition effects on soil carbon sequestration, through influencing the ratio between carbon gains $(C-i n)$ and losses $(C$-out $)$. Taken from De Deyn et al. (2008), with the agreement of Wiley

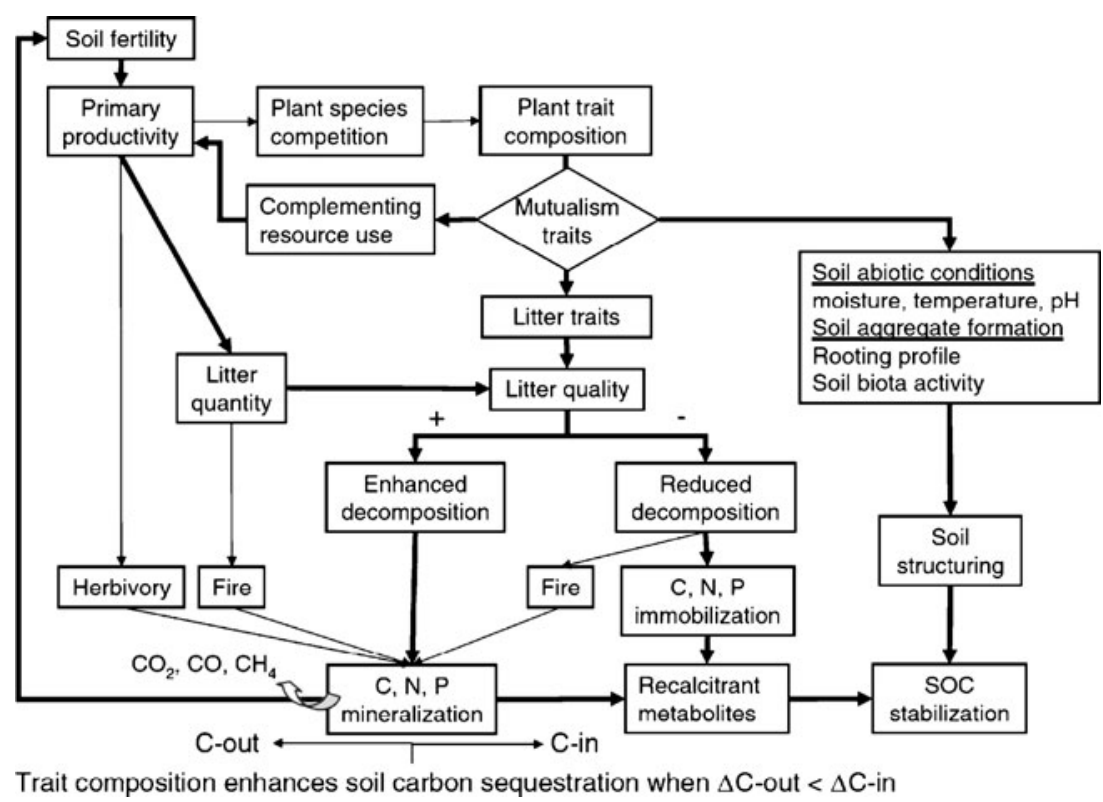


nitrogen, CWM of life cycle, vertical distribution of canopy structure, SLA and rooting depth and FDvg of life cycle, area of leaves and vegetative height (all positive). However, using the selection procedure proposed by Díaz et al. (2007b), they found negative effects of FDvg for many traits. This points to the strong dependency of the conclusions on the statistical procedure used.

In most studies assessing the effects of FDvg on EP, these statistical effects were not clearly considered. This might explain why, in a number of studies, the effects of FDvg of different traits or combinations thereof were found to be either negative (Thompson et al. 2005; Mokany et al. 2008) or non-significant (Díaz et al. 2007b) for several properties. Only in the study by Klumpp and Soussana (2009), investigating the impact of abiotic (disturbance) and biotic factors in a temperate grassland on six EP, were effects of FDvg for several traits found to be all positive.

A clear assessment of the impact of FDvg on EP will require that statistical procedures be validated and standardised. Only when this is done will we be able to detect the importance of complementarity among species for the functioning of ecosystems in natural and semi-natural environments.

\subsection{The role of plant traits on ecosystem properties} in controlled experiments

The framework proposed by Díaz et al. (2007b) aims at understanding the relative roles of abiotic and biotic components on EP in semi-natural and natural environments, as discussed in the previous section. Although this approach has the advantage of being relevant for real ecosystems, it also carries an inherent inability to identify the direction of causation between the variables measured (but see the structural equation approach as applied by Grace et al. 2007). Manipulative experiments, in which species with contrasting attributes are grown in experimental gardens under identical, common conditions, have thus been designed to overcome this problem.

In some of these experiments, simple plant traits were found to correlate with several EP. In the study by Pontes et al. (2007) on 13 perennial C3 pasture species grown over 2 years at two levels of nitrogen supply under two cutting regimes, ANPP was found to be negatively related to LNC expressed on a fresh mass basis, while digestibility was found to increase (respectively decrease) with SLA (respectively LDMC). In monocultures of species from Mediterranean old fields grown at two levels of nitrogen supply, a multiple regression combining SLA and LNC explained 59\% of the variance in ANPP in the first year of growth (Fig. 12), while in the low nitrogen treatment of the same experiment, the soil water content assessed over the entire growing season (cf. Violle et al. 2007a) was found to

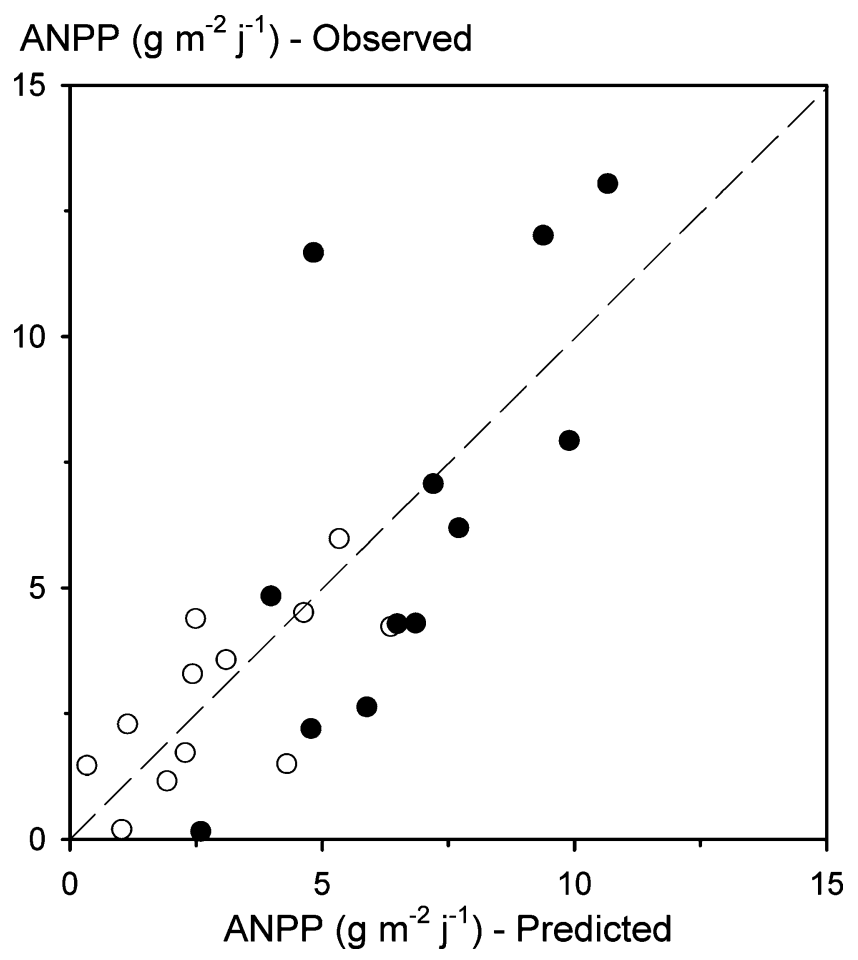

Fig. 12 Relationship between observed and predicted ANPP in a common garden experiment where 12 Mediterranean species from three successional stages were grown at high (black circles) and low (white circles) levels of nitrogen supply (Garnier et al., unpublished results). Predicted values are calculated from SLA and LNC of the different species as: $\mathrm{ANPP}=-5.86+0.22 \times \mathrm{SLA}+0.20 \times \mathrm{LNC}$ (correlation coefficient of regression between predicted and observed values: $\left.r^{2}=0.59 ; P<0.001, n=24\right)$. Details of the experiment can be found in Kazakou et al. (2007)

be negatively related to species rooting depth (Violle et al. 2009, Fig. 6b).

The large-scale 'Jena experiment', where 61 species common to Central European grasslands were grown in monocultures under similar environmental conditions, yielded more complex results after 4 months of growth (Heisse et al. 2007). Once the effects of seedling density were accounted for, differences in above-ground biomass production were based on variable combinations of traits, including time to seedling emergence, the vertical distribution of biomass along the stem, the size of individual shoots, the allocation of biomass between roots and shoots and some of the traits involved in the LES. No single combination of traits led to a high biomass production. Finally, Craine et al. (2002) grew 33 grasslands species for 5 years under low nitrogen availability and found that among non-legume species which produced and maintained large amounts of biomass were those with lower nitrogen concentrations in tissues, greater longevity of organs and higher root to shoot ratios. The two former correspond to traits identified in Berendse and Aerts's (1987) model as those allowing species to dominate 
nutrient-poor communities. Under these conditions of low nitrogen availability, Craine et al. (2002) also found that nitrogen fixation allowed legumes to produce greater biomass above-ground than other species with high stem biomass and low fine root productions.

These few experiments conducted under comparable conditions for a given set of species show that the combinations of traits influencing EP are likely to vary according to the environmental conditions chosen and the time scale of the experiment. In particular, results obtained over the short term should not be extrapolated on a longer term, especially in perennial species. It is likely that answers to this complex issue will be better tackled by combining such controlled experiments with observational/ manipulative experiments in the field and modelling.

\subsection{A different perspective: ecosystem allometry}

Ecosystem allometry is a recent perspective to the relationship between organisms and ecosystem functioning, which focuses on size distribution within communities (Enquist et al. 2003; Kerkhoff and Enquist 2006). It is clearly a traitbased approach, as size is one of the performance traits defined in Section 2.1, but here, the analysis is carried out without distinguishing the different plant species that compose the communities. The rationale, as applied to the study of primary productivity of plant communities (Kerkhoff and Enquist 2006), is briefly presented below.

By definition, NPP is the sum of the growth of all individuals present in the community. The allometric approach proposes that whole-plant individual growth rate (GR) can be written as:

$\mathrm{GR}=\beta_{g} \times M_{\text {plant }^{3 / 4}}$

where $\beta_{g}$ is the allometric coefficient relating growth rate to total plant mass $\left(M_{\text {plant }}\right)$. The $3 / 4$ scaling exponent reflects constraints on resource supply to individual cells (West et al. 1997). Empirical tests suggest that $\beta_{g}$ is constant across a wide range of photosynthetic organisms (Niklas and Enquist 2001), whatever the species considered. This implies that when the mass range is large, the size effect overrides any inter-specific differences in plant functioning. Kerkhoff and Enquist (2006) then suggested to group individuals of plant communities into $K$ size classes of average mass $M_{\text {plant }(k)}$ with similar growth rate. Ecosystem NPP can thus be written as:

$\mathrm{NPP}=\sum_{k=0}^{K} n_{k} \times \beta_{g} \times M_{\text {plant }(k)^{3 / 4}}$

where $n_{k}$ is the number of individuals in size class $k$ per square metre. Further development of this equation shows that NPP should be proportional to the $3 / 4$ power of total community phytomass (Kerkhoff and Enquist 2006), which is the sum of $M_{\text {plant }(k)}$ for all size classes. An empirical test across plant communities ranging from arctic tundra to tropical forests yielded, as expected, a log linear relationship between NPP and total community phytomass, but the scaling coefficient was substantially lower than predicted from theory (0.46 vs. 0.75: Kerkhoff and Enquist 2006). This was interpreted as a failure of the model to account for processes occurring within plant communities, such as asymmetry in light capture resulting from size hierarchies. In the same study, Kerkhoff and Enquist (2006) developed predictions for the scaling between community phytomass and nutrient mass (nitrogen and phosphorus), which were in closer agreement with empirical data.

Further testing of this approach is warranted, especially in situations where the biomass range of the communities compared is narrower: from arctic tundra to tropical forests, community biomass varies approximately 600 -fold, while in many cases, a much narrower range is of interest. Within grasslands, for example, differences of annual rainfall from 250 to $1,400 \mathrm{~mm} /$ year across the central grassland region of the USA induced a sevenfold range in biomass produced (Sala et al. 1988), and the continuous fertilisation of plots in the Park Grass Experiment (UK) during 150 years induced a threefold difference between the most and least productive treatments (Crawley et al. 2005). Over such reduced ranges, intrinsic differences in plant physiological properties among species might have impacts on ecosystem functioning beyond those of size.

\section{Plant traits in agricultural and forestry contexts}

In this section, we give examples of the use of traits in agricultural and forestry contexts. In doing so, we will identify the environmental gradients that are generated by human practices, and examine (1) the response traits to these gradients, be they generic or specific to the particular environmental conditions found in agricultural contexts; (2) the rules of community assembly and whether they differ from the general case; (3) how traits relate to ecosystem processes of agricultural importance.

\subsection{Grasslands}

Most experimental studies documenting the response of the functional structure of communities to gradients, and referred to so far in this paper, have been performed on grasslands. In this section, we selected only studies with an explicit agricultural perspective. In the following, it should be kept in mind that all types of grasslands have not been equally studied: in the literature, there is 
currently an over-representation of grazed situations over mown fields and very few studies have been conducted in grasslands characterised by an intensive use of fertilisers and sown species (Plantureux et al. 2009).

In grasslands, the defoliation regime (either grazing or mowing for hay making) and the supply of fertilisers appear as the main management practices affecting vegetation structure and functioning. The quantitative assessment of the impacts of defoliation is relatively difficult to characterise (cf. Garnier et al. 2007): it varies with the date of grazing or cutting, the time interval between two successive cutting or grazing periods especially during favourable seasons for growth and the amount of harvested or consumed biomass (Duru et al. 1998). Assessment of this impact requires regular measurement of standing biomass to take into account the seasonal variation of growth, the impact of dates of defoliation and compensatory re-growth after defoliation (McNaughton et al. 1996). These experimental limits explain why data from different studies are hardly comparable except when treatments contrast intensive grazing to very low or absence of grazing (Louault et al. 2005; Evju et al. 2009).

Although the assessment of nutrient limitation could theoretically be done through soil measurements, there is currently no simple method to assess the amount of nutrients a given soil can release and make available to plants. This has led to the development of nutrient indices for nitrogen and phosphorus (Duru and Ducrocq 1997; Lemaire and Gastal 1997), which are the main limiting nutrients for grassland production. These indices, which reflect the growth limitation by nutrient availability, allow one to quantify changes in nutrient level due to fertilisation or grazing management.

The traits of species that respond to management practices in grasslands are the same as those responding to the same selective pressures in non-managed areas. For example, leaf traits such as SLA or LDMC are strongly modulated by nutrient availability (Duru et al. 1998; McIntyre 2008). Grazing affects a large series of traits: a high grazing pressure generally favours annual over perennial plants, short plants over tall plants, prostrate over erect plants and species with stoloniferous and rosette architecture over those with a tussock architecture; the timing of defoliation also impacts on phenology, including leaf senescence (Duru et al. 1998; Louault et al. 2005; Diaz et al. 2007; Kahmen and Poschlod 2008; Romermann et al. 2008).

A recent meta-analysis examined whether the welldocumented negative effect of land use intensification on species richness results in a similar decline in the FD of plant communities (Flynn et al. 2009). These authors assumed that there were three possibilities: a similar decrease in species richness and FD with intensification; a faster decrease in FD than in species richness, revealing that functionally unique species are lost first; a lower decrease in FD than in species richness, showing that functionally redundant species are lost first. The outcome of the analysis revealed that most grasslands showed a faster decline in FD than in species richness. However, this relationship seems to depend on environment, as illustrated by a comparative study performed in Mongolia (Sasaki et al. 2009a, b). This study suggests that faster loss in FD than in species richness occurs with increasing grazing intensity in harsh environments, whereas functionally redundant species are lost first in benign conditions.

A trait-based approach to grassland management also appears to be promising. In particular, biomass production, the date of peak production and the digestibility of herbage can be predicted from leaf traits and/or plant height (Al Haj Khaled et al. 2006; Pontes et al. 2007; Ansquer et al. 2009b). Furthermore, the FDvg of LDMC correlates closely with the variation in biomass production around the peak of herbage mass, a variable of importance for managers, which gives information on the temporal flexibility of herbage use (Ansquer et al. 2009b). On the basis of these results, a set of easily recognised species with similar functional traits (LDMC and phenology) can be used to infer ecosystem processes of agricultural importance (Ansquer et al. 2009a).

Other functions of grasslands can also be deduced from trait values. For example, in Australia, the role of grasslands to limit soil erosion has been negatively related to traits determining high production, achieved there by reduced plant cover with low persistence (McIntyre 2008).

A major question for research is to define which practices may favour the constancy of ecosystem processes of grasslands under global changes. This challenge is of importance knowing that a significant number of traditional 'stress-tolerant' grassland species have been replaced over the last century by more ruderal species with faster growth and shorter life span (Van Calster et al. 2008; Walker et al. 2009), with probable major impact on future primary production of grasslands.

\subsection{Crop weed communities}

Over the last decades, the weed flora had dramatically changed in response to shift in management practices. On the one hand, new rules for integrated weed management aiming at reducing the use of herbicides and preserving the biodiversity of agroecosystems is currently leading to the emergence of more diverse communities. On the other hand, there are still highly specialised crops in which a specialised weed flora occurs in response to specific techniques and pesticide use. Since a decrease in the use of herbicides is likely to occur in such systems for both technical and social reasons (Aubertot et al. 2007; Wezel et 
al. 2009), the switch to practices other than pesticide applications may well result in an increasing diversity of weed species. The use of traits may be an opportunity to detect groups of weedy species which similarly respond to a set of practices or affect crop yield.

Major variations in weed composition between fields are associated with human management factors: current crop type, preceding crop type, soil $\mathrm{pH}$ and texture, land drainage (Fried et al. 2008; Butler et al. 2009; Hawes et al. 2009). Crop type includes the effects of sowing season, herbicide families and fertilisation regimes, which induce specific light conditions affecting growth phenology (Lososova et al. 2008). It is noticeable that differences in weed diversity between genetically modified herbicidetolerant crop varieties and conventional varieties are much lower than between different crop species (Freckleton et al. 2003). Within individual crop types, the landscape organisation (occurrence of hedges and meadows) and/or tillage depth are also of importance (Smith 2006; Butler et al. 2009). Across all phases of the rotation, however, weed community structure is affected more by the current identity of the crop than by the number of crops in the rotation (Smith and Gross 2007).

New flora responding to current change in management can be characterised using the same set of traits as those measured on spontaneous vegetation (Booth and Swanton 2002). Weed species selected against over the past 60 years in cereal and soybean crops in UK have a short stature, large seeds and flower late (Storkey et al. 2010). As a consequence, exclusion from intensive systems over time is explained by low competitive ability in high fertility treatment in relation to low stature and low resilience to herbicide influence due to low reproductive output. By contrast, the current weed flora occurring in intensive systems is highly specialised, in terms of resource use, phenology and tolerance to herbicides. For example, weeds increasing in abundance in sunflower crops since the 1970s belong to a 'sunflower-mimicking' functional group: they are more nitrophilous and heliophilous, less sensitive to sunflower herbicides and share a rapid summer life cycle, independently of phylogeny (Fried et al. 2009). Characterisation of these responses by traits is not always straightforward. Herbicide tolerance is partly explained by leaf anatomy and architecture, cuticle thickness and phenology but also depends on physiological characteristics that are not easily measurable. Plant response to sowing time or tillage includes germination syndrome and life cycle, both of which influence how species respond to changes in soil resource levels and light availability driven by seasonal disturbance regime (Smith 2006). On the other hand, the weed flora in extensively managed systems, where disturbances are irregular and of varying spatial extent, is composed of lessspecialised species sharing characteristics with colonisers or ruderal species (Lososova et al. 2006): they resemble the species with short stature, large seeds and late flowering that occurred in cultivated areas years ago and have been excluded by intensification (Storkey et al. 2010).

The different flora found under contrasted weed management also differ in FD: the reduction of FD in intensive cropping systems may occur through increased specialisation rather than by further enhanced spread of the most generalist species (Fried et al. 2009), whereas FD in extensive places increases in relation to the occurrence of less-specialised species (Lososova et al. 2006).

Combining weed and crop characteristics is a further step to assess the impact of the FD of the weed-crop community on EP. Weed size relative to that of the crop is a major parameter impacting final crop yield in cropweed models (e.g. Kropff et al. 1992; Booth and Swanton 2002). In addition, recent research suggests that the ability of weeds to draw on resource pools other than that of crops, which can be assessed by differences in root depth and architecture (Deen et al. 2003; Smith et al. 2009), may be related to lower weed-crop competition (Smith et al. 2009). This means that the FDvg of the crop-weed community defined with traits related to resource use could be of major importance to predict crop yield: a high FDvg-inducing complementary in resource use by weeds and crop across time or space should result in a reduced impact of weeds on crops.

Weeds can also have an impact on the local biodiversity. In extensively managed areas, the diversity of the local weed flora has been shown to correlate negatively with herbivore load and outbreaks of pests and positively with number of non-pest invertebrate species (Hawes et al. 2005). A recent study showed that functional types of weeds, defined by categorical traits, can be used to assess that of invertebrates (Hawes et al. 2009). However, a similar study performed in UK showed that a number of weeds that have a high importance for invertebrates and birds are classified as noxious considering their large negative impact on crops (Storkey 2006), which should refrain farmers to conserve them in non-extensive areas.

\subsection{Forests}

The utility of traits for forest management in temperate areas has not been clearly established yet, as most forests are composed of one or a few species, taken among a set of approximately ten well-known species. The recent emphasis on other services than biomass production (regulation of climate and flood, support for biogeochemical cycles and biodiversity, supplying of recreational values, etc.), which cannot be achieved through traditionally managed forests, initiated the proposal of more 'nature-orientated' management. This on-going change is characterised by the 
increasing importance of natural regeneration that can lead to the establishment of mixed forests. As a consequence, future management of forests will require knowledge on species different from the original set, in order to predict successful establishment and biomass production of mixed stands.

The identification of traits linked to the successful establishment of mixed forests from natural regeneration is an on-going effort and shows that shade tolerance detected by wood density and SLA are probably of major importance (Janse-ten Klooster et al. 2007). In trees, most comparative experiments have been performed in tropical species (Poorter and Rose 2005; Muller-Landau et al. 2008). This implies that relationships between seedling establishment and adult traits are not clearly established for most species found in temperate environments (but see Kaelke et al. 2001; Stancioiu and O'Hara 2006).

The recent damages caused to forests by extreme climatic events such as storms and severe droughts demonstrate the urgent need for large comparisons of species according to functions which have not been characterised so far. The identification of relevant and easily measured traits related to drought, wind tolerance and root anchorage that could be used to monitor routine selection of species appears as an important research need in this respect (Cochard et al. 2008; Hallik et al. 2009; Stokes et al. 2009).

The likely increasing importance of mixed forests and the search for higher resistance to disturbances (Vila et al. 2007) is an opportunity to test the usefulness of traits for forest management. This could be done by building on previous work performed in tropical areas where the high species diversity of forests was a strong incentive to identify functional groups for management of biomass production and maintenance of species diversity (Vanclay et al. 1997; Gourlet-Fleury et al. 2005; Kooyman and Rossetto 2008).

\section{Trait databases and ecoinformatics}

\subsection{Availability of trait data}

The methodology of screening for traits, which takes its roots in the seminal work by Grime and Hunt (1975) for RGR, has progressively built up over the last three decades. This has led to the constitution of large data sets of plant traits allowing us to address general questions pertaining to plant functioning and evolution. This includes the detection of (1) broad relationships among traits, such as allometric scaling (West et al. 1999; Enquist and Niklas 2002; Reich et al. 2006) and trade-offs (Wright et al. 2004; Bolmgren and Cowan 2008) at various levels of organisation, (2) the phylogenetic signal on traits (Moles et al. 2005a; Watanabe et al. 2007; Flores et al., submitted manuscript), (3) the relationships between plant traits and environmental factors at continental or global scales (Reich and Oleksyn 2004; Moles et al. 2005a; Pakeman et al. 2008; Moles et al. 2009; Ordoñez et al. 2009).

Although these data sets constitute an invaluable wealth for the scientific community as a whole, their compatibility, accessibility and further dissemination remain problematic. Some data sets are available as appendices to original publications (e.g. the Glopnet data set: Wright et al. 2004; the wood data set: Chave et al. 2009) or as ecological archives (e.g. fire-related traits of species from the Mediterranean basin: Paula et al. 2009), and several attempts have been made to develop publicly accessible plant trait databases (CLO-PLA2: Klimes and Klimesova 1999; BiolFlor: Kühn et al. 2004; LEDA: Kleyer et al. 2008). However, this concerns only a small proportion of the data potentially available, and a comprehensive approach to data storing, management and retrieval for plant based research is currently lacking. This involves devoting specific efforts to data integration, whose aim is to organise and structure the data currently stored in distributed repositories and in heterogeneous formats, and make them available in easily and widely usable format. Beyond integration, such efforts would provide substantial added value to the data, which could then also be used in contexts different from those in which these were initially collected for or for other, more general questions. These issues have led to the recent development of ecoinformatics and the realisation of the importance of metadata and ontologies as applied to the field of ecology.

\subsection{Towards a trait-based ecoinformatics}

This issue as applied to traits falls under the broader perspective of what is now called 'ecoinformatics', defined as 'a field of research and development focused on the interface between ecology, computer science, and information technology' and considered as the new bioinformatics (Jones et al. 2006). The recent development of ecoinformatics results from the acknowledgement that data sharing and integration should become leading priorities in ecology, as this has been recognised three decades ago in molecular biology (Stein 2008).

Madin et al. (2008) have proposed an architecture for ecological and environmental data management involving three levels. The first level is composed of data stored within distributed data repositories, while the third, higher level is composed of software tools used by scientists and data managers to work on the data. Madin et al. (2008) stress that an intermediate level is required between these two, in order to develop tools that are more effective for 
querying, integrating, analysing and publishing data from the raw material available in data repositories. Metadata standards and ontologies are two key elements of this level.

Metadata may be defined as 'information about data', i.e. the information required to understand data, including data set contents, context, structure and accessibility (Michener et al. 1997). Examples of metadata include the identification of who conducted an experiment (name of observer, institution, storage location and form, etc.), where (latitude, longitude, altitude, etc.) and how it was conducted (measuring device, precision, etc.), and so on. A number of benefits are attached to the production of metadata in addition to data (Scurlock et al. 2002; Michener 2006). These include increased data longevity, facilitation of data reuse by those who have produced the data, data sharing with others, data mining for purposes and questions other than those for which data collection was initially designed for. This is all the more important that databases may outlive the original investigator and that ecological research requires integration and synthesis from a wide range of disciplines (Jones et al. 2006; Michener 2006). Several metadata content specifications could be used to document ecological data (Michener et al. 1997), but at this time, there is no generally accepted format for metadata standards in ecology (Scurlock et al. 2002), and their use is not widespread. This certainly applies to the field of trait-based research, which needs specific efforts to improve its practices in this respect.

A second aspect concerns the development of core and specialised ontologies, a key step in the formalisation of concepts in a particular field of research. In the information sciences, ontology is a formal model of knowledge covering a specified discipline in which (1) each element (e.g. field name or column in a database) is precisely defined and (2) each possible relationship between data elements is parameterised or constrained (Schuurman and Leszczynski 2008). Owing to the formal logical structure of ontologies, computer-based reasoning systems can use them to draw inferences or conclusions, enabling ontologies to help identify important aspects of a data set that were hidden or implicit (Jones et al. 2006). For example, if one is looking for data on SLA, it might be stored in distributed databases under a variable named 'SLA' or its inverse 'LMA'. Both variables will first have to be precisely defined in a controlled vocabulary, and an ontology would capture the idea that SLA=1/LMA. Any query addressed to the distributed databases through the ontology filter will then extract automatically data stored under the different variable headings. Some general ontologies have been developed for ecology, such as, e.g. OBOE (Extensible Observation Ontology: Madin et al. 2007), which provides ecologists with a formal framework for ecological observations and associated measures and protocols. A primary objective is thus to develop a domain ontology relevant for a trait-based approach to ecology, compatible with highlevel ontologies such as OBOE. This can be done using related specialised ontologies such as plant ontology (Jaiswal et al. 2002) or plant growth stage ontology (Pujar et al. 2006) as starting points.

This whole approach to data management constitutes a first step towards the long-term objective of ecological data integration and sharing through the development of information systems comparable to those currently used for gene sequences and protein data (GenBank, EMBL) or taxonomic diversity (GBIF: Guralnick et al. 2007).

\section{Conclusions and perspectives}

In this review, we have highlighted a number of strengths of the trait-based approach to address questions pertaining to plant and ecosystem functioning, community dynamics and species distribution in ecological contexts and some selected agronomical situations. Although the focus was on plants, there is now increasing recognition that traits might be useful tools to address questions relative to other organisms as well, be they invertebrate or vertebrate animals (cf. de Bello et al. 2010) or microorganisms (Green et al. 2008). This functional characterisation of biodiversity that traits make possible enables us to bring insights which go well beyond what is possible when species are merely described by Latin binomials.

Several types of factors were decisive to the major breakthroughs in plant trait research that have taken place over the past 15 years. First, the imperious need to predict changes in vegetation in response to global change drivers has triggered the search for simplification of floristic complexity; second, the identification of a small set of easily measured traits relevant to plant functioning and distribution that could be measured on a wide array of species and situations worldwide was decisive; third, a set of consistent concepts and hypotheses allowing us to scale from the individual to higher levels of organisation proved very powerful; fourth, the design of protocols to measure traits in a standardised way and the recognition that sharing data and information among scientists working in different systems were essential to progress.

Challenges ahead to trait-based research pertain to a number of aspects. In terms of plant functioning, whether, e.g. further axes of variation can be detected in plants, including some involving root dimensions and whether any easily measured traits can be related to the various aspects of the regeneration niche (sensu Grubb 1977) and to demographic parameters such as population birth and death rate appear as central issues. At the community level, understanding the mechanisms through which species traits, as driven by environmental factors and biotic interactions, 
determine its functional structure will require theoretical, experimental and modelling approaches. Whether phylogeny has a prominent role in these mechanisms is currently a highly debated topic (e.g. Cavender-Bares et al. 2009). This will also require a search for a better identification and quantification of the environmental gradients driving trait responses. There are some initiatives in this direction (e.g. Knevel et al. 2005; Garnier et al. 2007; Bartholomeus et al. 2008; Ordoñez et al. 2009), but a general agreement on a minimum set of required environmental variables and standardised protocols to measure them is still lacking. At the ecosystem level, the understanding of how and which traits (in terms of values and ranges) affect processes, properties and services remains very preliminary. It is also essential to recognise that simultaneous effects on multiple, linked ecosystem processes and services are involved (reviewed in de Bello et al. 2010) and that scaling from traits to services requires innovating approaches allowing us to bridge the gap between biological and social sciences (cf. de Chazal et al. 2008). Predictions at all scales will also require an increased coupling to modelling approaches, from ecophysiological/ecosystem levels (e.g. Martineau and Saugier 2007; van Wijk 2007) to that of the whole biosphere (e.g. Prentice et al. 2007). Last but not least, further progress will depend on the continued development of trait databases and information systems allowing scientists from different disciplines (taxonomy, ecology, environmental sciences, etc.) to share and combine their data to tackle broad-scale and complex questions in ecology.

The prospects to apply a comparative approach based on traits in the field of agronomy are wide. Intensive agricultural systems, where crop diversity is reduced to one or very few species that are generally genetically homogeneous and where external inputs are often supplied in large quantities, are increasingly criticised for their negative environmental impacts (Giller et al. 1997; Aubertot et al. 2007; Le Roux et al. 2009; Wezel et al. 2009; Griffon 2010). Reducing these impacts will involve reducing, e.g. the use of fertilisers and/or pesticides and rely more on regulations involving a wider range of diverse organisms (e.g. soil organisms for the control of fertility and non-pest insects/microorganisms for the biological control of pests). As shown in the case of grasslands (Section 6.1), trait-based tools might be used for the management of these more complex systems where a detailed mechanistic and modelling approach based on indepth knowledge of all organisms involved will probably not be tractable. At the other end of the spectrum, Malézieux et al. (2009) advocated the use of functional traits (or groups) to characterise and model complex multispecies cropping systems, such as agroforestry systems, on which a majority of the world's farmer depend, particularly in tropical regions (Swift and Anderson 1993; Malézieux et al. 2009). For this transfer from ecological to agronomical science to succeed, the specificities of these various agricultural systems, such as the identity and strength of the selective pressures acting in these environments (e.g. types and return times of specific disturbances such as tillage and/or selective pesticide applications), will have to be identified, at the same time as the responses of the organisms themselves, which may not have been described as yet in less artificial situations. Le Roux et al. (2009, chapter 1) have discussed these issues in the special case of the impacts of agricultural practices on biodiversity.

As nicely put by Westoby et al. (2002), 'There is much to be done. There is also a real hope that we may be getting somewhere'. And getting somewhere will involve continued and enhanced collaboration across disciplines ranging from ecophysiology to macroecology, crossing experimental and theoretical approaches as applied to natural and man-modified systems.

Acknowledgments We thank Guillaume Fried, Hendrik Davy and Jean-Claude Gégout for providing us with references illustrating the use of traits for weed and forest management. Isabelle Mougenot and Cyrille Violle critically reviewed several parts of the manuscript. This publication has benefited from the continuous exchanges of people and ideas in the framework of GDR 2574 'TRAITS' (CNRS, France).

\section{References}

Aber JD, Mellilo JM (2001) Terrestrial ecosystems. Brooks/Cole, Pacific Grove

Ackerly DD (2003) Community assembly, niche conservatism, and adaptive evolution in changing environments. Int J Plant Sci 164 (3):S165-S184. doi:10.1086/368401

Ackerly D (2004) Functional strategies of chaparral shrubs in relation to seasonal water deficit and disturbance. Ecol Monog 74:25-44. doi: $10.1890 / 03-4022$

Ackerly DD, Cornwell WK (2007) A trait-based approach to community assembly: partitioning of species trait values into within- and among-community components. Ecol Lett 10:135145. doi:10.1111/j.1461-0248.2006.01006.x

Ackerly DD, Monson RK (2003) Waking the sleeping giant: the evolutionary foundations of plant functions. Int J Plant Sci 164 (3):S1-S6. doi:10.1086/374729

Ackerly DD, Schwilk DW, Webb CO (2006) Niche evolution and adaptive radiation: testing the order of trait divergence. Ecology 87(7):S50-S61. doi:10.1890/0012-9658(2006)87[50:NEAART] 2.0.CO;2

Aerts R (1997) Climate, leaf litter chemistry and leaf litter decomposition in terrestrial ecosystems: a triangular relationship. Oikos 79:439-449

Aerts R, Chapin FS III (2000) The mineral nutrition of wild plants revisited: a re-evaluation of processes and patterns. Adv Ecol Res 30:1-67. doi:10.1016/S0065-2504(08)60016-1

Al Haj Khaled R, Duru M, Decruyenaere V, Jouany C, Cruz P (2006) Using leaf traits to rank native grasses according to their nutritive value. Rangeland Ecol Manage 59:648-654. doi:10.2111/05031R2.1 
Albert CH, Thuiller W, Yoccoz NG, Soudant A, Boucher F, Saccone P, Lavorel S (2010) Intraspecific functional variability: extent, structure and sources of variation. J Ecol 98:604-613. doi:10.1111/j.1365-2745.2010.01651.x

Altesor A, Oesterheld M, Leoni E, Lezama F, Rodrìguez C (2005) Effect of grazing exclosure on community structure and productivity of a Uruguayan grassland. Plant Ecol 179:83-91. doi:10.1007/s11258-004-5800-5

Ansquer P, Duru M, Theau JP, Cruz P (2009a) Convergence in plant traits between species within grassland communities simplifies their monitoring. Ecol Indic 9(5):1020-1029. doi:10.1016/j. ecolind.2008.12.002

Ansquer P, Duru M, Theau JP, Cruz P (2009b) Functional traits as indicators of fodder provision over a short time scale in speciesrich grasslands. Ann Bot 103(1):117-126. doi:10.1093/aob/ $\operatorname{men} 215$

Arnold SJ (1983) Morphology, performance and fitness. Am Zool 23:347-361. doi:10.1093/icb/23.2.347

Aubertot J-N, Barbier J-M, Carpentier A, Gril J-J, Guichard L, Lucas P, Savary S, Voltz M (eds) (2007) Pesticides, agriculture et environnement. Réduire l'utilisation des pesticides et en limiter les impacts environnementaux. Quae, Versailles

Baker TR, Phillips OL, Laurance WF, Pitman NCA, Almeida S, Arroyo L, DiFiore A, Erwin T, Higuchi N, Killeen TJ, Laurance SG, Nascimento H, Monteagudo A, Neill DA, Silva JNM, Malhi Y, Lòpez GG, Peacock J, Quesada CA, Lewis SL, Lloyd J (2009) Do species traits determine patterns of wood production in Amazonian forests? Biogeosci 6:297-307. doi:10.5194/bg-6-297-2009

Balvanera P, Pfisterer AB, Buchmann N, He J-S, Nakashizuka T, Raffaelli D, Schmid B (2006) Quantifying the evidence for biodiversity effects on ecosystem functioning and services. Ecol Lett 9:1146-1156. doi:10.1111/j.1461-0248.2006.00963.x

Bartholomeus RP, Witte J-PM, van Bodegom PM, Aerts R (2008) The need of data harmonization to derive robust empirical relationships between soil conditions and vegetation. J Veg Sci 19:799808. doi: $10.3170 / 2008-8-18450$

Bazzaz FA, Ackerly DD, Reekie EG (2000) Reproductive allocation in plants. In: Fenner M (ed) Seeds. The ecology of regeneration in plant communities. CAB International, Wallingford, pp 1-29

Belyea LR, Lancaster J (1999) Assembly rules within a contingent ecology. Oikos 86:402-416

Berendse F, Aerts R (1987) Nitrogen-use-efficiency: a biologically meaningful definition ? Funct Ecol 1:293-296

Bernhardt-Romermann M, Romermann C, Nuske R, Parth A, Klotz S, Schmidt W, Stadler J (2008) On the identification of the most suitable traits for plant functional trait analyses. Oikos 117 (10):1533-1541. doi:10.1111/j.0030-1299.2008.16776.x

Bolmgren K, Cowan PD (2008) Time-size tradeoffs: a phylogenetic comparative study of flowering time, plant height ans seed mass in a north-temperate flora. Oikos 117:424-429. doi:10.1111/ j.2007.0030-1299.16142.x

Booth BD, Swanton CJ (2002) Assembly theory applied to weed communities. Weed Sci 50(1):2-13. doi:10.1614/0043-1745 (2002)050[0002:AIATAT]2.0.CO;2

Boulant N, Kunstler G, Rambal S, Lepart J (2008) Seed supply, drought, and grazing determine spatio-temporal patterns of recruitment for native and introduced invasive pines in grasslands. Divers Distrib 14:862-874. doi:10.1111/j.1472-4642.2008.00494.x

Bradshaw AD (1987) Functional ecology: comparative ecology? Funct Ecol 1:71

Butler SJ, Brooks D, Feber RE, Storkey J, Vickery JA, Norris K (2009) A cross-taxonomic index for quantifying the health of farmland biodiversity. J Appl Ecol 46(6):1154-1162. doi:10.1111/j.1365-2664.2009.01709.x

Cadotte MW, Cavender-Bares J, Tilman D, Oakley TH (2009) Using phylogenetic, functional and trait diversity to understand patterns of plant community productivity. PLoS ONE 4(5):e5695. doi:10.1371/journal.pone.0005695

Cadotte MW, Davies TJ, Regetz J, Kembel SW, Cleland E, Oakley TH (2010) Phylogenetic diversity metrics for ecological communities: integrating species richness, abundance and evolutionary history. Ecol Lett 13(1):96-105. doi:10.1111/j.14610248.2009.01405.x

Calow P (1987) Towards a definition of functional ecology. Funct Ecol 1:57-61

Cardinale BJ, Srivastava DS, Duffy JE, Wright JP, Downing AL, Sankaran M, Jouseau C (2006) Effects of biodiversity on the functioning of trophic groups and ecosystems. Nature 443:989992. doi:10.1038/nature05202

Cardinale BJ, Wright JP, Cadotte MW, Carroll IT, Hector A, Srivastava DS, Loreau M, Weis JJ (2007) Impacts of plant diversity on biomass production increase through time because of species complementarity. P Natl Acad Sci USA 104:1812318128. doi:10.1073/pnas.0709069104

Cavender-Bares J, Keen A, Miles B (2006) Phylogenetic structure of Floridian plant communities depends on taxonomic and spatial scale. Ecology 87(7):S109-S122. doi:10.1890/0012-9658(2006) 87[109:PSOFPC]2.0.CO;2]

Cavender-Bares J, Kozak KH, Fine PVA, Kembel SW (2009) The merging of community ecology and phylogenetic biology. Ecol Lett 12:693-715. doi:10.1111/j.1461-0248.2009.01314.x

Cebrián J, Duarte CM (1995) Plant growth-rate dependence of detrital carbon storage in ecosystems. Science 268:1606-1608. doi:10.1126/science.268.5217.1606

Chapin FS III (1980) The mineral nutrition of wild plants. Annu Rev Ecol Syst 11:233-260

Chapin FS III (1993) Functional role of growth forms in ecosystem and global processes. In: Ehleringer JR, Field CB (eds) Scaling physiological processes. Leaf to globe. Academic, San Diego, pp 287-312

Chapin FS III, Autumn K, Pugnaire F (1993) Evolution of suites of traits in response to environmental stress. Am Nat 142:S78-S92. doi: $10.1086 / 285524$

Chapin FS III, Zavaleta ES, Eviner VT, Naylor RL, Vitousek PM, Reynolds HL, Hooper DU, Lavorel S, Sala OE, Hobbie SE, Mack MC, Díaz S (2000) Consequences of changing biodiversity. Nature 405:234-242. doi:10.1038/35012241

Chapin FS III, Matson PA, Mooney HA (2002) Principles of terrestrial ecosystem ecology. Springer, New York

Chave J, Andalo C, Brown S, Cairns MA, Chambers JQ, Eamus D, Fölster H, Fromard F, Higuchi N, Kira T, Lescure J-P, Nelson BW, Ogawa H, Puig H, Riéra B, Yamakura T (2005) Tree allometry and improved estimation of carbon stocks and balance in tropical forests. Oecologia 145:87-99. doi:10.1007/s00442005-0100-x

Chave J, Coomes D, Jansen S, Lewis SL, Swenson NG, Zanne AE (2009) Towards a worldwide wood economics spectrum. Ecol Lett 12:351-366. doi:10.1111/j.1461-0248.2009.01285.x

Cingolani AM, Cabido M, Gurvich DE, Renison D, Díaz S (2007) Filtering processes in the assembly of plant communities: are species presence and adundance driven by the same traits? J Veg Sci 18:911-920. doi:0.1111/j.1654-1103.2007.tb02607.x

Cochard H, Barigah ST, Kleinhentz M, Eshel A (2008) Is xylem cavitation resistance a relevant criterion for screening drought resistance among Prunus species? J Plant Physiol 165(9):976982. doi:10.1016/j.jplph.2007.07.020

Cornelissen JHC, Thompson K (1997) Functional leaf attributes predict litter decomposition rate in herbaceous plants. New Phytol 135:109-114. doi:10.1046/j.1469-8137.1997.00628.x

Cornelissen JHC, Pérez-Harguindeguy N, Díaz S, Grime JP, Marzano B, Cabido M, Vendramini F, Cerabolini B (1999) Leaf structure and defence control litter decomposition rate across species and 
life forms in regional flora on two continents. New Phytol 143:191-200. doi:10.1046/j.1469-8137.1999.00430.x

Cornelissen JHC, Cerabolini B, Castro-Díez P, Villar-Salvador P, Montserrat-Martí G, Puyravaud JP, Maestro M, Werger MJA, Aerts R (2003a) Functional traits of woody plants: correspondence of species rankings between field adults and laboratorygrown seedlings? J Veg Sci 14:311-322. doi:10.1111/j.16541103.2003.tb02157.x

Cornelissen JHC, Lavorel S, Garnier E, Díaz S, Buchmann N, Gurvich DE, Reich PB, ter Steege H, Morgan HD, van der Heijden MGA, Pausas JG, Poorter H (2003b) A handbook of protocols for standardised and easy measurement of plant functional traits worldwide. Aust J Bot 51:335-380. doi:10.1071/BT02124

Cornwell WK, Ackerly DD (2009) Community assembly and shifts in plant trait distributions across an environmental gradient in coastal California. Ecol Monog 79:109-126. doi:10.1890/071134.1

Cornwell WK, Schwilk DW, Ackerly DD (2006) A trait-based test for habitat filtering: convex hull volume. Ecology 87(6):1465-1471. doi:10.1890/0012-9658(2006)87[1465:ATTFHF]2.0.CO;2

Cornwell WK, Cornelissen JHC, Amatangelo K, Dorrepaal E, Eviner VT, Godoy O, Hobbie SE, Hoorens B, Kurokawa H, PérezHarguindeguy N, Quested HM, Santiago LS, Wardle DA, Wright IJ, Aerts R, Allison SD, van Bodegom P, Brovkin V, Chatain A, Callaghan TV, Díaz S, Garnier E, Gurvich DE, Kazakou E, Klein JA, Read J, Reich PB, Soudzilovskaia NA, Vaieretti MV, Westoby M (2008) Plant traits are the dominant control on litter decomposition rates within biomes worldwide. Ecol Lett 11:1065-1071. doi:10.1111/j.1461-0248.2008.01219.x

Cortez J, Garnier E, Pérez-Harguindeguy N, Debussche M, Gillon D (2007) Plant traits, litter quality and decomposition in a Mediterranean old-field succession. Plant Soil 296:19-34. doi:10.1007/s11104-007-9285-6

Craine JM (2009) Resource strategies of wild plants. Princeton University Press, Princeton

Craine JM, Tilman D, Wedin D, Reich P, Tjoelker M, Knops J (2002) Functional traits, productivity and effects on nitrogen cycling of 33 grassland species. Funct Ecol 16:563-574. doi:10.1046/ j.1365-2435.2002.00660.x

Crawley MJ, Johnston AE, Silvertown J, Dodd M, de Mazencourt C, Heard MS, Henman DF, Edwards GR (2005) Determinants of species richness in the Park Grass Experiment. Am Nat 165:179192. doi: $10.1086 / 427270$

de Bello F, Thuiller W, Leps J, Choler P, Clement JC, Macek P, Sebastia MT, Lavorel S (2009) Partitioning of functional diversity reveals the scale and extent of trait convergence and divergence. J Veg Sci 20(3):475-486. doi:10.1111/j.16541103.2009.01042.x

de Bello F, Lavorel S, Díaz S, Harrington R, Cornelissen JHC, Bardgett RD, Berg MP, Cipriotti P, Feld CK, Hering D, Martins da Silva P, Potts SG, Sandin L, Sousa JP, Storkey J, Wardle DA, Harrison PA (2010) Towards an assessment of multiple ecosystem processes and services via functional traits. Biodivers Conserv 19:2873-2893. doi:10.1007/s10531-0109850-9

de Chazal J, Quétier F, Lavorel S, Van Doorn A (2008) Including multiple differing stakeholder values into vulnerability assessments of socio-ecological systems. Glob Environ Chang 18:508520. doi:10.1016/j.gloenvcha.2008.04.005

de Deyn GB, Cornelissen JHC, Bardgett RD (2008) Plant functional traits and soil carbon sequestration in contrasting biomes. Ecol Lett 11:516-531. doi:10.1111/j.1461-0248.2008.01164.x

Deen W, Cousens R, Warringa J, Bastiaans L, Carberry P, Rebel K, Riha S, Murphy C, Benjamin LR, Cloughley C, Cussans J, Forcella F, Hunt T, Jamieson P, Lindquist J, Wang E (2003) An evaluation of four crop: weed competition models using a common data set. Weed Res 43(2):116-129. doi:10.1046/ j.1365-3180.2003.00323.x

Diamond JM (1975) Assembly of species communities. In: Cody ML, Diamond JM (eds) Ecology and evolution of communities. Belknap, Cambridge, pp 342-444

Díaz S, Cabido M (2001) Vive la différence: plant functional diversity matters to ecosystem processes. Trends Ecol Evol 16:646-655. doi: $10.1234 / 12345678$

Diaz S, Lavorel S, McIntyre S, Falczuk V, Casanoves F, Milchunas DG, Skarpe C, Rusch G, Sternberg M, Noy-Meir I, Landsberg J, Zhang W, Clark H, Campbell BD (2007) Plant trait responses to grazing - a global synthesis. Glob Change Biol 13(2):313-341. doi:10.1111/j.1365-2486.2006.01288

Díaz S, Fargione J, Chapin FS III, Tilman D (2006) Biodiversity loss threatens human well-being. PLoS Biol 4(8):e277. doi:10.1371/ journal.pbio.0040277

Díaz S, Lavorel S, Chapin FS III, Tecco PA, Gurvich DE, Grigulis K (2007a) Functional diversity - at the crossroads between ecosystem functioning and environmental filters. In: Canadell JG, Pataki DE, Pitelka LF (eds) Terrestrial ecosystems in a changing world. Springer, Berlin, pp 81-91

Díaz S, Lavorel S, de Bello F, Quétier F, Grigulis K, Robson M (2007b) Incorporating plant functional diversity effects in ecosystem service assessments. P Natl Acad Sci USA 104:20684-20689. doi:10.1073/pnas.0704716104

Duarte CM, Sand-Jensen K, Nielsen SL, Enríquez S, Agustí S (1995) Comparative functional ecology: rationale and potentials. Trends Ecol Evol 10:418-421. doi:10.1016/S0169-5347 (00)89163-6

Duru M, Ducrocq H (1997) A nitrogen and phosphorus herbage nutrient index as a tool for assessing the effect of $\mathrm{N}$ and $\mathrm{P}$ supply on the dry matter yield of permanent pastures. Nutr Cycl Agroecosyst 47:59-69

Duru M, Balent G, Gibon A, Magda D, Theau JP, Cruz P, Jouany C (1998) Fonctionnement et dynamique des prairies permanentes. Exemple des pyrenees centrales. Fourrages 153:97-113

Eckstein RL, Karlsson PS, Weih M (1999) Leaf life span and nutrient resorption as determinants of plant nutrient conservation in temperate-arctic regions. New Phytol 143:177-189. doi:10.1046/j.1469-8137.1999.00429.x

Enquist BJ, Niklas KJ (2002) Global allocation rules for patterns of biomass partitioning in seed plants. Science 295:1517-1520. doi: $10.1126 /$ science. 1066360

Enquist BJ, Economo EP, Huxman TE, Allen AP, Ignace DD, Gilloly JF (2003) Scaling metabolism from organisms to ecosystems. Nature 423:639-642. doi:10.1038/nature01671

Eviner VT, Chapin FS III (2003) Functional matrix: a conceptual framework for predicting multiple plant effects on ecosystems. Annu Rev Ecol Syst 34:455-485. doi:10.1146/annurev. ecolsys.34.011802.132342

Evju M, Austrheim G, Halvorsen R, Mysterud A (2009) Grazing responses in herbs in relation to herbivore selectivity and plant traits in an alpine ecosystem. Oecologia 161:77-85. doi:10.1007/ s00442-009-1358-1

Fayolle A (2008) Structure des communautés de plantes herbacées sur les Grands Causses: stratégies fonctionnelles des espèces et interactions spécifiques. PhD thesis SupAgro Montpellier (ED SIBAGHE), Montpellier, p 225

Fenner M, Thompson K (2005) The ecology of seeds. Cambridge University Press, Cambridge

Flynn DFB, Gogol-Prokurat M, Nogeire T, Molinari N, Richers BT, Lin BB, Simpson N, Mayfield MM, DeClerck F (2009) Loss of functional diversity under land use intensification across multiple taxa. Ecol Lett 12(1):22-33. doi:10.1111/ j.1461-0248.2008.01255.x 
Fortunel C, Garnier E, Joffre R, Kazakou E, Quested H, Grigulis K, Lavorel S, Ansquer P, Castro H, Cruz P, Dolezal J, Eriksson O, Freitas H, Golodets C, Jouany C, Kigel J, Kleyer M, Lehsten V, Lepš J, Meier T, Pakeman R, Papadimitriou M, Papanastasis VP, Quétier F, Robson M, Sternberg M, Theau J-P, Thébault A, Zarovali M (2009a) Leaf traits capture the effects of land use changes and climate on litter decomposability of grasslands across Europe. Ecology 90:598-611. doi:10.1890/08-0418.1

Fortunel C, Violle C, Roumet C, Buatois B, Navas M-L, Garnier E (2009b) Allocation strategies and seed traits are hardly affected by nitrogen supply in 18 species differing in successional status. Perspect Plant Ecol Evol Syst 11:267-283. doi:10.1016/j. ppees.2009.04.003

Freckleton RP, Sutherland WJ, Watkinson AR (2003) Deciding the future of GM crops in Europe. Science 302(5647):994-996. doi:10.1126/science.1092671

Freschet GT, Cornelissen JHC, van Logtestijn RSP, Aerts R (2010) Evidence of the 'plant economics spectrum' in a subarctic flora. $\mathrm{J}$ Ecol 98:362-373. doi:10.1111/j.1365-2745.2009.01615.x

Fried G, Norton LR, Reboud X (2008) Environmental and management factors determining weed species composition and diversity in France. Agr Ecosyst Environ 128:68-76. doi:10.1016/j. agee.2008.05.003

Fried G, Chauvel B, Reboud X (2009) A functional analysis of largescale temporal shifts from 1970 to 2000 in weed assemblages of sunflower crops in France. J Veg Sci 20(1):49-58. doi:10.1111/ j.1654-1103.2009.05284.x

Fukami T, Bezemer TM, Mortimer SR, van der Putten WH (2005) Species divergence and trait convergence in experimental plant community assembly. Ecol Lett 8(12):1283-1290. doi:10.1111/ j.1461-0248.2005.00829.x

Garnier E, Aronson J (1998) Nitrogen use efficiency from leaf to stand level: clarifying the concept. In: Lambers $\mathrm{H}$, Poorter $\mathrm{H}$, van Vuuren MMI (eds) Inherent variation in plant growth. Physiological mechanisms and ecological consequences. Backhuys, Leiden, pp 515-538

Garnier E, Laurent G (1994) Leaf anatomy, specific mass and water content in congeneric annual and perennial grass species. New Phytol 128:725-736. doi:10.1111/j.1469-8137.1994.tb04036.x

Garnier E, Laurent G, Bellmann A, Debain S, Berthelier P, Ducout B, Roumet C, Navas M-L (2001a) Consistency of species ranking based on functional leaf traits. New Phytol 152:69-83. doi:10.1046/j.0028-646x.2001.00239.x

Garnier E, Shipley B, Roumet C, Laurent G (2001b) A standardized protocol for the determination of specific leaf area and leaf dry matter content. Funct Ecol 15:688-695. doi:10.1046/j.02698463.2001.00563.x

Garnier E, Cortez J, Billès G, Navas M-L, Roumet C, Debussche M, Laurent G, Blanchard A, Aubry D, Bellmann A, Neill C, Toussaint J-P (2004) Plant functional markers capture ecosystem properties during secondary succession. Ecology 85(9):26302637. doi:10.1890/03-0799

Garnier E, Lavorel S, Ansquer P, Castro H, Cruz P, Dolezal J, Eriksson O, Fortunel C, Freitas H, Golodets C, Grigulis K, Jouany C, Kazakou E, Kigel J, Kleyer M, Lehsten V, Lepš J, Meier T, Pakeman R, Papadimitriou M, Papanastasis VP, Quested H, Quétier F, Robson M, Roumet C, Rusch G, Skarpe M, Sternberg M, Theau J-P, Thébault A, Vile D, Zarovali M (2007) Assessing the effects of land use change on plant traits, communities and ecosystem functioning in grasslands: a standardized methodology and lessons from an application to 11 European sites. Ann Bot 99:967-985. doi:10.1093/aob/ $\operatorname{mcl} 215$

Gaudet CL, Keddy PA (1988) A comparative approach to predicting competitive ability from plant traits. Nature 334:242-243. doi: $10.1038 / 334242 \mathrm{a} 0$
Gilbert B, Lechowicz MJ (2004) Neutrality, niches, and dispersal in a temperate forest understory. P Natl Acad Sci USA 101 (20):7651-7656. doi:10.1073/pnas.0400814101

Giller KE, Beare MH, Lavelle P, Izac MN, Swift MJ (1997) Agricultural intensification, soil biodiversity and agroecosystem function. Appl Soil Ecol 6:3-16. doi:10.1016/S0929-1393(96)00149-7

Gitay H, Noble IR (1997) What are funtional types and how should we seek them? In: Smith TM, Shugart HH, Woodward FI (eds) Plant funtional types. Their relevance to ecosystem properties and global change. Cambridge University Press, Cambridge, pp. 3-19

Gourlet-Fleury S, Blanc L, Picard N, Sist P, Dick J, Nasi R, Swaine MD, Forni E (2005) Grouping species for predicting mixed tropical forest dynamics: looking for a strategy. Ann For Sci 62:785-796. doi:10.1051/forest:2005084

Gower ST (2002) Productivity of terrestrial ecosystems. In: Mooney HA, Canadell JG (eds) The Earth system: biological and ecological dimensions of global environmental change. Wiley, New York, pp 516-521

Grace JB, Anderson TM, Smith MD, Seabloom E, Andelman SJ, Meche G, Weiher E, Allain LK, Jutila H, Sankaran M, Knops J, Ritchie M, Willig MR (2007) Does species diversity limit productivity in natural grassland communities? Ecol Lett 10:680-689. doi:10.1111/j.1461-0248.2007.01058.x

Green JL, Bohannan BJM, Whitaker RJ (2008) Microbial biogeography: from taxonomy to traits. Science 320:1039-1043. doi: $10.1126 /$ science. 1153475

Greene DF, Johnson EA (1989) A model of wind dispersal of winged or plumed seeds. Ecology 70:339-347. doi:10.2307/1937538

Griffon M (2010) Pour des agricultures écologiquement intensives, Editions de l'Aube, La Tour d'Aigues

Grime JP, Hunt R (1975) Relative growth-rate: its range and adaptive significance in a local flora. J Ecol 63:393-422. http://www.jstor. org/stable/2258728

Grime JP (1977) Evidence for the existence of three primary strategies in plants and its relevance to ecological and evolutionary theory. Am Nat 111:1169-1194. doi:10.1086/283244

Grime JP (1979) Plant strategies and vegetation processes. Wiley, Chichester

Grime JP (1997) Biodiversity and ecosystem function: the debate deepens. Science 277:1260-1261. doi:10.1126/science.277.5330.1260

Grime JP (1998) Benefits of plant diversity to ecosystems: immediate, filter and founder effects. J Ecol 86:902-910. doi:10.1046/ j.1365-2745.1998.00306.x

Grime JP (2001) Plant strategies, vegetation processes, and ecosystem properties. Wiley, Chichester

Grime JP (2006) Trait convergence and trait divergence in herbaceous plant communities: mechanisms and consequences. J Veg Sci 17 (2):255-260. doi:10.1111/j.1654-1103.2006.tb02444.x

Grime JP, Anderson JM (1986) Environmental controls over organism activity. In: Van Cleve K, Chapin FSI, Flanagan PW, Viereck LA, Dyrness CT (eds) Forest ecosystems in Alaskan taïga: a synthesis of structure and function. Springer, Berlin, pp 89-95

Grime JP, Thompson K, Hunt R, Hodgson JG, Cornelissen JHC, Rorison IH, Hendry GAF, Ashenden TW, Askew AP, Band SR, Booth RE, Bossard CC, Campbell BD, Cooper JEL, Davison AW, Gupta PL, Hall W, Hand DW, Hannah MA, Hillier SH, Hodkinson DJ, Jalili A, Liu Z, Mackey JML, Matthews N, Mowforth MA, Neal AM, Reader RJ, Reiling K, Ross-Fraser W, Spencer RE, Sutton F, Tasker DE, Thorpe PC, Whitehouse J (1997) Integrated screening validates primary axes of specialisation in plants. Oikos 79:259-281

Gross N, Robson TM, Lavorel S, Albert C, Le Bagousse-Pinguet Y, Guillemin R (2008) Plant response traits mediate the effects of subalpine grasslands on soil moisture. New Phytol 180:652-662. doi:10.1111/j.1469-8137.2008.02577.x 
Grubb PJ (1977) The maintenance of species-richness in plant communities: the importance of the regeneration niche. Biol Rev 52:107-145. doi:10.1111/j.1469-185X.1977.tb01347.x

Guralnick RP, Hill AP, Lane M (2007) Towards a collaborative, global infrastructure for biodiversity assessment. Ecol Lett 10:663-672. doi:10.1111/j.1461-0248.2007.01063.x

Hallik L, Niinemets U, Wright IJ (2009) Are species shade and drought tolerance reflected in leaf-level structural and functional differentiation in Northern Hemisphere temperate woody flora? New Phytol 184(1):257-274. doi:10.1111/j.14698137.2009.02918.x

Harper JL, Lovell PH, Moore KG (1970) The shapes and sizes of seeds. Annu Rev Ecol Syst 1:327-356

Harrison SP, Prentice IC, Barboni D, Kohfeld KE, Ni J, Sutra JP (2010) Ecophysiological and bioclimatic foundations for a global plant functional classification. J Veg Sci 21(2):300-317. doi:10.1111/j.1654-1103.2009.01144.x

Hawes C, Begg GS, Squire GR, Iannetta PPM (2005) Individuals as the basic accounting unit in studies of ecosystem function: functional diversity in shepherd's purse, Capsella. Oikos 109 (3):521-534. doi:10.1111/j.0030-1299.2005.13853.x

Hawes C, Haughton AJ, Bohan DA, Squire GR (2009) Functional approaches for assessing plant and invertebrate abundance patterns in arable systems. Basic Appl Ecol 10(1):34-42. doi:10.1016/j.baae.2007.11.007

Heisse K, Roscher C, Schuhmacher J, Schulze E-D (2007) Establishment of grassland species in monocultures: different strategies lead to success. Oecologia 152:435-447. doi:10.1007/s00442007-0666-6

Hendry GAF, Grime JP (eds) (1993) Methods in comparative plant ecology. Chapman \& Hall, London

Hobbie SE, Oleksyn J, Eissenstat DM, Reich PB (2010) Fine root decomposition rates do not mirror those of leaf litter among temperate tree species. Oecologia 162:505-513. doi:10.1007/ s00442-009-1479-6

Hodgson JG, Montserrat-Martí G, Cerabolini B, Ceriani RM, Maestro-Martí M, Peco B, Wilson PJ, Thompson K, Grime JP, Band SR, Bogard A, Castro-Díez P, Charles M, Jones G, PérezRontomé MC, Caccianiga M, Alard D, Bakker JP, Cornelissen JHC, Dutoit T, Grootjans AP, Guerrero-Campo J, Gupta PL, Hynde A, Kahmen S, Poschlod P, Romo-Díez A, Rorison IH, Rosén E, Schreiber K-F, Tallowin J, de Torres EL, VillarSalvador P (2005) A functional method for classifying European grasslands for use in joint ecological and economic studies. Basic Appl Ecol 6:119-131. doi:10.1016/j.baae.2005.01.006

Hooper DU, Chapin FS III, Ewel JJ, Hector A, Inchausti P, Lavorel S, Lawton JH, Lodge DM, Loreau M, Naeem S, Schmid B, Setälä H, Symstad AJ, Vandermeer J, Wardle DA (2005) Effects of biodiversity on ecosystem functioning: a consensus of current knowledge. Ecol Monog 75:3-35. doi:10.1890/04-0922

Hughes L, Dunlop M, French K, Leishman MR, Rice B, Rodgerson L, Westoby M (1994) Predicting dispersal spectra: a minimal set of hypotheses based on plant attributes. J Ecol 82:933-950

Hummel I, Vile D, Violle C, Devaux J, Ricci B, Blanchard A, Garnier E, Roumet C (2007) Relating root structure and anatomy to whole plant functioning: the case of fourteen herbaceous Mediterranean species. New Phytol 173:313-321. doi:10.1111/ j.1469-8137.2006.01912.x

Jaiswal P, Ware D, Ni J, Chang K, Zhao W, Schmidt S, Pan X, Clark K, Teytelman L, Cartinhour S, Stein L, McCouch SR (2002) Gramene: development and integration of trait and gene ontologies for rice. Comp Funct Genomics 3:132-136. doi:10.1002/cfg. 156

Jakobsson A, Eriksson O (2000) A comparative study of seed number, seed size, seedling size and recruitment in grassland plants. Oikos 88:494-502. doi:10.1034/j.1600-0706.2000.880304.x
Janse-ten Klooster SH, Thomas EJP, Sterck FJ (2007) Explaining interspecific differences in sapling growth and shade tolerance in temperate forests. J Ecol 95:1250-1260. doi:10.1111/j.13652745.2007.01299.x

Jones MB, Schildhauer MP, Reichman OJ, Bowers S (2006) The new bioinformatics: integrating ecological data from the gene to the biosphere. Annu Rev Ecol Syst 37:519-544. doi:10.1146/ annurev.ecolsys.37.091305.110031

Kaelke CM, Kruger EL, Reich PB (2001) Trade-offs in seedling survival, growth, and physiology among hardwood species of contrasting successional status along a light-availability gradient. Can J Bot 31(9):1602-1616. doi:10.1139/cjfr-31-9-1602

Kahmen S, Poschlod P (2008) Effects of grassland management on plant functional trait composition. Agr Ecosyst Environ 128 (3):137-145. doi:10.1016/j.agee.2008.05.016

Kazakou E, Garnier E, Navas M-L, Roumet C, Collin C, Laurent G (2007) Components of nutrient residence time and the leaf economics spectrum in species from Mediterranean old-fields differing in successional status. Funct Ecol 21:235-245. doi:10.1111/j.1365-2435.2006.01242.x

Kazakou E, Violle C, Roumet C, Pintor C, Gimenez O, Garnier E (2009) Litter quality and decomposability of species from a Mediterranean succession depend on leaf traits but not on nitrogen supply. Ann Bot 104:1151-1161. doi:10.1093/aob/mcp202

Keddy P (1992a) Assembly and response rules: two goals for predictive community ecology. J Veg Sci 3:157-164. doi: $10.2307 / 3235676$

Keddy PA (1992b) A pragmatic approach to functional ecology. Funct Ecol 6:621-626

Keith DA, Holman L, Rodoreda S, Lemmon J, Bedward M (2007) Plant functional types can predict decade-scale changes in fireprone vegetation. J Ecol 95(6):1324-1337. doi:10.1111/j.13652745.2007.01302.x

Kerkhoff AJ, Enquist BJ (2006) Ecosystem allometry: the scaling of nutrient stocks and primary productivity across plant communities. Ecol Lett 9:419-427. doi:10.1111/j.14610248.2006.00888.x

King DA (1990) The adaptive significance of tree height. Am Nat 135:809-828. doi:10.1086/285075

Kleyer M, Bekker RM, Knevel IC, Bakker JP, Thompson K, Sonnenschein M, Poschlod P, van Groenendael JM, Klimes L, Klimesova J, Klotz S, Rusch GM, Hermy M, Adriaens D, Boedeltje G, Bossuyt B, Dannemann A, Endels P, Gotzenberger L, Hodgson JG, Jackel AK, Kuhn I, Kunzmann D, Ozinga WA, Romermann C, Stadler M, Schlegelmilch J, Steendam HJ, Tackenberg O, Wilmann B, Cornelissen JHC, Eriksson O, Garnier E, Peco B (2008) The LEDA Traitbase: a database of life-history traits of the Northwest European flora. J Ecol 96 (6): 1266-1274. doi:10.1111/j.1365-2745.2008.01430.x

Klimes L, Klimesova J (1999) CLO-PLA2 - a database of clonal plants in Central Europe. Plant Ecol 141:9-19

Klumpp K, Soussana J-F (2009) Using functional traits to predict grassland ecosystem change: a mathematical test of the responseand-effect trait approach. Glob Change Biol 15:2921-2934. doi:10.1111/j.1365-2486.2009.01905.x

Knevel IC, Bekker RM, Kunzmann D, Stadler M, Thompson K (eds) (2005) The LEDA traitbase. Collecting and measuring standards of life-history traits of the Northern European flora. University of Groningen, Groningen

Kooyman R, Rossetto M (2008) Definition of plant functional groups for informing implementation scenarios in resource-limited multi-species recovery planning. Biodivers Conserv 17 (12):2917-2937. doi:10.1007/s10531-008-9405-5

Kraft NJB, Valencia R, Ackerly D (2008) Functional traits and nichebased tree community assembly in an Amazonian forest. Science 322:580-582. doi:10.1126/science. 1160662 
Kropff MJ, Weaver SE, Smits MA (1992) Use of ecophysiological models for crop-weed interference: relations amongst weed density, relative time of weed emergence, relative leaf area and yield loss. Weed Sci 40:296-301

Kühn I, Durka W, Klotz S (2004) BiolFlor-a new plant-trait database as a tool for plant invasion ecology. Divers Distrib 10:363-365. doi:10.3170/2007-8-18349

Kuparinen A (2006) Mechanistic models for wind dispersal. Trends Plant Sci 11:296-301. doi:10.1016/j.tplants.2006.04.006

Larcher W (2003) Physiological plant ecology: ecophysiology and stress physiology of functional groups. Springer, Berlin

Lavorel S, Garnier E (2002) Predicting changes in community composition and ecosystem functioning from plant traits: revisiting the Holy Grail. Funct Ecol 16:545-556. doi:10.1046/j.13652435.2002.00664.x

Lavorel S, Mcintyre S, Landsberg J, Forbes TDA (1997) Plant functional classifications: from general groups to specific groups based on response to disturbance. Trends Ecol Evol 12(12):474478. doi:10.1016/S0169-5347(97)01219-6

Lavorel S, Díaz S, Cornelissen JHC, Garnier E, Harrison SP, McIntyre S, Pausas J, Pérez-Harguindeguy N, Roumet C, Urcelay C (2007) Plant functional types: are we getting any closer to the Holy Grail? In: Canadell J, Pataki D, Pitelka L (eds) Terrestrial ecosystems in a changing world. Springer, Berlin, pp 149-164

Lavorel S, Grigulis K, McIntyre S, Williams NSG, Garden D, Dorrough J, Berman S, Quetier F, Thebault A, Bonis A (2008) Assessing functional diversity in the field-methodology matters! Funct Ecol 22(1):134-147. doi:10.1111/j.1365-2435.2007.01339.x

Le Roux X, Barbault R, Baudry J, Burel F, Doussan I, Garnier E, Herzog F, Lavorel S, Lifran R, Roger-Estrade J, Sarthou J-P, Trommetter M (eds) (2009) Agriculture et biodiversité. Valoriser les synergies. Quae, Versailles

Leishman MR, Westoby M (1998) Seed size and shape are not related to persistence in soil in Australia in the same way as in Britain. Funct Ecol 12:480-485. doi:10.1046/j.1365-2435.1998.00215.x

Leishman MR, Wright IJ, Moles AT, Westoby M (2000) The evolutionary ecology of seed size. In: Fenner M (ed) Seeds: the ecology of regeneration in plant communities. $\mathrm{CAB}$ International, Wallingford, pp 31-57

Lemaire G, Gastal F (1997) N uptake and distribution in plant canopies. In: Lemaire G (ed) Diagnosis of the nitrogen status in the crops. Springer, Berlin, pp 3-44

Leoni E, Altesor A, Paruelo JM (2009) Explaining patterns of primary production from individual level traits. J Veg Sci 20:612-619. doi:10.1111/j.1654-1103.2009.01080.x

Lepš J, de Bello F, Lavorel S, Berman S (2006) Quantifying and interpreting functional diversity of natural communities: practical considerations matter. Preslia 78:481-501

Loreau M, Naeem S, Inchausti P, Bengtsson J, Grime JP, Hector A, Hooper DU, Huston MA, Raffaelli D, Schmid B, Tilman D, Wardle DA (2001) Biodiversity and ecosystem functioning: current knowledge and future challenges. Science 294:804-808. doi:10.1126/science. 1064088

Lortie CJ, Aarssen LW (1999) The advantage of being tall: higher flowers receive more pollen in Verbascum thapsus L. (Scrophulariaceae). EcoScience 6:68-71

Lortie CJ, Brooker RW, Choler P, Kikvidze Z, Michalet R, Pugnaire FI, Callaway RM (2004) Rethinking plant community theory. Oikos 107(2):433-438. doi:10.1111/j.00301299.2004.13250.x

Lososova Z, Chytry M, Kuhn I, Hajek O, Horakova V, Pysek P, Tichy L (2006) Patterns of plant traits in annual vegetation of manmade habitats in central Europe. Perspect Plant Ecol Evol 8 (2):69-81. doi:10.1016/j.ppees.2006.07.001

Lososova Z, Chytry M, Kuehn I (2008) Plant attributes determining the regional abundance of weeds on central European arable land. J Biogeogr 35(1):177-187. doi:10.1111/j.13652699.2007.01778.x

Louault F, Pillar VD, Aufrère J, Garnier E, Soussana J-F (2005) Plant traits and functional types in response to reduced disturbance in a semi-natural grassland. J Veg Sci 16:151-160. doi:10.1658/11009233(2005)016[0151:PTAFTI]2.0.CO;2

Madin J, Bowers S, Schildhauer M, Krivov S, Pennington D, Villa F (2007) An ontology for describing and synthesizing ecological observation data. Ecol Inf 2:279-296. doi:10.1016/j. ecoinf.2007.05.004

Madin JS, Bowers S, Schildhauer MP, Jones MB (2008) Advancing ecological research with ontologies. Trends Ecol Evol 23:159168. doi:10.1016/j.tree.2007.11.007

Malézieux E, Crozat Y, Dupraz C, Laurans M, Makowski D, OzierLafontaine H, Rapidel B, de Tourdonnet S, Valantin-Morison M (2009) Mixing plant species in cropping systems: concepts, tools and models. A review. Agron Sustain Dev 29:43-62. doi:10.1051/ agro:2007057

Martineau Y, Saugier B (2007) A process-based model of old field succession linking ecosystem and community ecology. Ecol Model 204:399-419. doi:10.1016/j.ecolmodel.2007.01.023

Mason NWH, MacGillivray K, Steel JB, Wilson JB (2003) An index of functional diversity. J Veg Sci 14(4):571-578. doi:10.1111/ j.1654-1103.2003.tb02184.x

Mason NWH, Mouillot D, Lee WG, Wilson JB (2005) Functional richness, functional evenness and functional divergence: the primary components of functional diversity. Oikos 111:112-118. doi:10.1111/j.0030-1299.2005.13886.x

McGill BJ, Enquist BJ, Weiher E, Westoby M (2006) Rebuilding community ecology from functional traits. Trends Ecol Evol 21:178-185. doi:10.1016/j.tree.2006.02.002

McIntyre S (2008) The role of plant leaf attributes in linking land use to ecosystem function in temperate grassy vegetation. Agr Ecosyst Environ 128(4):251-258. doi:10.1016/j.agee.2008.06.015

McIntyre S, Lavorel S, Landsberg J, Forbes TDA (1999) Disturbance response in vegetation-towards a global perspective on functional traits. J Veg Sci 10:621-630. doi: $10.2307 / 3237077$

McKane RB, Johnson LC, Shaver GR, Nadelhoffer KJ, Rastetter EB, Fry B, Giblin AE, Kielland K, Kwiatkowski BL, Laundre JA, Murray G (2002) Resource-based niches provide a basis for plant species diversity and dominance in arctic tundra. Nature 415 (6867):68-71. doi:10.1038/415068a

McNaughton SJ, Milchunas DG, Franck DA (1996) How can net primary productivity be measured in grazing ecosystems? Ecology 77(3):974-977. doi:10.2307/2265518

Meinzer FC, Andrade JL, Goldstein G, Holbrook NM, Cavelier J, Wright SJ (1999) Partitioning of soil water among canopy trees in a seasonally dry tropical forest. Oecologia 121:293-301

Michener WK (2006) Meta-information concepts for ecological data management. Ecol Inf 1:3-7. doi:10.1016/j.ecoinf.2005.08.004

Michener WK, Brunt JW, Helly JJ, Kirchner TB, Stafford SG (1997) Nongeospatial metadata for the ecological sciences. Ecol Appl 7:330-342. doi:10.1890/1051-0761(1997)007[0330:NMFTES] 2.0.CO;2]

Mitchell P, Veneklaas E, Lambers H, Burgess S (2008) Using multiple trait associations to define hydraulic functional types in plant communities of south-western Australia. Oecologia 158(3):385397. doi:10.1007/s00442-008-1152-5

Mokany K, Ash J (2008) Are traits measured on pot grown plants representative of those in natural communities? J Veg Sci 19:119-126. doi:10.3170/2007-8-18340

Mokany K, Ash J, Roxburgh S (2008) Functional identity is more important than diversity in influencing ecosystem processes in a temperate native grassland. J Ecol 96:884-893. doi:10.1111/ j.1365-2745.2008.01395.x 
Moles AT, Leishman MR (2008) The seedling as part of a plant's life history strategy. In: Leck MA, Parker VT, Simpson RL (eds) Seedling ecology and evolution. Cambridge University Press, Cambridge, pp 217-238

Moles AT, Ackerly DD, Webb CO, Tweddle JC, Dickie JB, Pitman AJ, Westoby M (2005a) Factors that shape seed mass evolution. P Natl Acad Sci USA 102:10540-10544. doi:10.1073/ pnas.0501473102

Moles AT, Ackerly DD, Webb CO, Tweddle JC, Dickie JB, Westoby M (2005b) A brief history of seed size. Science 307:576-580. doi:10.1126/science.1104863

Moles AT, Warton DI, Warman L, Swenson NG, Laffan SW, Zanne AE, Pitman A, Hemmings FA, Leishman MR (2009) Global patterns in plant height. J Ecol 97(5):923-932. doi:10.1111/ j.1365-2745.2009.01526.x

Muller-Landau HC, Wright SJ, Calderon O, Condit R, Hubbell SP (2008) Interspecific variation in primary seed dispersal in a tropical forest. J Ecol 96(4):653-667. doi:10.1111/j.13652745.2008.01399.x

Naeem S, Bunker DA, Hector A, Loreau M, Perrings C (eds) (2009) Biodiversity, ecosystem functioning, and human wellbeing - an ecological and economic perspective. Oxford University Press, New York City

Navas ML, Violle C (2009) Plant traits related to competition: how do they shape the functional diversity of communities? Community Ecol 10(1):131-137. doi:10.1556/ComEc.10.2009.1.15

Navas ML, Roumet C, Bellmann A, Laurent G, Garnier E (2010) Suites of plant traits in species from different stages of a Mediterranean secondary succession. Plant Biol Stuttg 12 (1):183-196. doi:10.1111/j.1438-8677.2009.00208.x

Niinemets Ü (2001) Global-scale climatic controls of leaf dry mass per area, density, and thickness in trees and shrubs. Ecology 82(2):453469. doi:10.1890/0012-9658(2001)082[0453:GSCCOL]2.0.CO;2]

Niklas KJ (1995a) Plant height and the properties of some herbaceous stems. Ann Bot 75:133-142. doi:10.1006/anbo.1995.1004

Niklas KJ (1995b) Size-dependent allometry of tree height, diameter and trunk-taper. Ann Bot 75:217-227. doi:10.1006/ anbo. 1995.1015

Niklas KJ, Enquist BJ (2001) Invariant scaling relationships for interspecific plant biomass production rates and body size. P Natl Acad Sci USA 98:2922-2997. doi:10.1073/pnas.041590298

Ordoñez JC, van Bodegom PM, Witte J-PM, Wright IJ, Reich PB, Aerts R (2009) A global study of relationships between leaf traits, climate and soil measures of nutrient fertility. Glob Ecol Biogeogr 18:137-149. doi:10.1111/j.1466-8238.2008.00441.x

Oren O, Sperry JS, Katul GG, Pataki DE, Ewers BE, Phillips N, Schäfer KVR (1999) Survey and synthesis of intra- and interspecific variation in stomatal sensitivity to vapour pressure deficit. Plant Cell Environ 22:1515-1526. doi:10.1046/j.1365-3040.1999.00513.x

Pakeman RJ, Garnier E, Lavorel S, Ansquer P, Castro H, Cruz P, Doležal J, Eriksson O, Freitas H, Golodets C, Kigel J, Kleyer M, Lepš J, Meier T, Papadimitriou M, Papanastasis VP, Quested H, Quétier F, Rusch G, Sternberg M, Theau J-P, Thébault A, Vile D (2008) Impact of abundance weighing on the response of seed traits to climate and land use change. J Ecol 96:355-366. doi:10.1111/j.1365-2745.2007.01336.x

Paula S, Arianoutsou M, Kazanis D, Tavsanoglu C, Lloret F, Buhk C, Ojeda F, Luna B, Moreno JM, Rodrigo A, Espelta JM, Palacio S, Fernández-Santos B, Fernandes PM, Pausas JG (2009) Firerelated traits for plant species of the Mediterranean Basin. Ecology 90:1420. doi:10.1890/08-1309.1

Pausas JG, Bradstock RA, Keith DA, Keeley JE, Fire Network GCTE (2004) Plant functional traits in relation to fire in crown-fire ecosystems. Ecology 85(4):1085-1100. doi:10.1890/02-4094

Pérez-Harguindeguy N, Díaz S, Cornelissen JHC, Vendramini F, Cabido M, Castellanos A (2000) Chemistry and toughness predict leaf litter decomposition rates over a wide spectrum of functional types and taxa in central Argentina. Plant Soil 218:2130. doi:10.1023/A:1014981715532

Petchey OL, Gaston KJ (2006) Functional diversity: back to basics and looking forward. Ecol Lett 9:741-758. doi:10.1111/j.14610248.2006.00924.x

Petchey OL, Hector A, Gaston KJ (2004) How do different measures of functional diversity perform? Ecology 85(3):847-857. doi: $10.1890 / 03-0226$

Pickett STA, Bazzaz FA (1978) Organization of an assemblage of early successional species on a soil moisture gradient. Ecology 59:1248-1255. doi:10.2307/1938238

Plantureux S, Bellon S, Burel F, Chauvel B, Dajoz I, Guy P, Lelievre V, Ranjard L, Roger-Estrade J, Sarthou J-P, Viaux P (2009) Prospective Agriculture Biodiversité. INRA Département Environnement Agronomie, Montpellier, p 310

Pontes LDS, Soussana J-F, Louault F, Andueza D, Carrère P (2007) Leaf traits affect the above-ground productivity and quality of pasture grasses. Funct Ecol 21:844-853. doi:10.1111/j.13652435.2007.01316.x

Poorter H, Garnier E (2007) Ecological significance of inherent variation in relative growth rate and its components. In: Pugnaire FI, Valladares F (eds) Functional plant ecology, 2nd edn. CRC, Boca Raton, pp 67-100

Poorter L, Rose S (2005) Light-dependent changes in the relationship between seed mass and seedling traits: a meta-analysis for rain forest tree species. Oecologia 142(3):378-387. doi:10.1007/ s00442-004-1732-y

Prentice IC, Bondeau A, Cramer W, Harrison SP, Hickler T, Lucht W, Sitch S, Smith B, Sykes MT (2007) Dynamic global vegetation modeling: quantifying terrestrial ecosystem responses to largescale environmental change. In: Canadell J, Pitelka LF, Pataki D (eds) Terrestrial ecosystems in a changing world. Springer, Berlin, pp 175-192

Prior LD, Eamus D, Bowman DMJS (2003) Leaf attributes in the seasonally dry tropics: a comparison of four habitats in northern Australia. Funct Ecol 17:504-515. doi:10.1046/ j.1365-2435.2003.00761.x

Pugnaire F, Valladares F (eds) (2007) Functional plant ecology. CRC, Boca Raton

Pujar A, Jaiswal P, Kellogg EA, Ilic K, Vincent L, Avraham S, Stevens P, Zapata F, Reiser L, Rhee SY, Sachs MM, Schaeffer M, Stein L, Ware D, McCouch SR (2006) Whole plant growth stage ontology for angiosperms and its application in plant biology. Plant Physiol 142:414-428. doi:10.1104/pp.106.085720

Quested H, Eriksson O, Fortunel C, Garnier E (2007) Plant traits relate to whole-community litter quality and decomposition following land use change. Funct Ecol 21:1016-1026. doi:10.1111/j.13652435.2007.01324.x

Quétier F, Thébault A, Lavorel S (2007) Plant traits in a state and transition framework as markers of ecosystem response to landuse change. Ecol Monog 77:33-52. doi:10.1890/06-0054

Raunkiaer C (1934) The life forms of plants and statistical plant geography. Oxford University Press, Oxford

Rees M (1997) Evolutionary ecology of seed dormancy and seed size. In: Silvertown J, Franco M, Harper JL (eds) Plant life histories. Ecology, phylogeny and evolution. The Royal Society, Cambridge, pp 121-142

Rees M, Venable DL (2007) Why do big plants make big seeds? J Ecol 95:926-936. doi:10.1111/j.1365-2745.2007.01277.x

Reich PB, Oleksyn J (2004) Global patterns of plant leaf N and P in relation to temperature and latitude. P Natl Acad Sci USA 101:11001-11006. doi:10.1073/pnas.0403588101

Reich PB, Walters MB, Ellsworth DS (1992) Leaf life-span in relation to leaf, plant, and stand characteristics among diverse ecosystems. Ecol Monog 62:365-392. doi:10.2307/2937116 
Reich PB, Walters MB, Ellsworth DS (1997) From tropics to tundra: global convergence in plant functioning. Proc Nat Acad Sci USA 94:13730-13734

Reich PB, Tjoelker MG, Machado J-L, Oleksyn J (2006) Universal scaling of respiratory metabolism, size and nitrogen in plants. Nature 439:457-461. doi:10.1038/nature04282

Roche P, Díaz BN, Gachet S (2004) Congruency analysis of species ranking based on leaf traits: which traits are the more reliable? Plant Ecol 174:37-48

Roderick ML, Berry SL, Noble IR, Farquhar GD (1999) A theoretical approach to linking the composition and morphology with the function of leaves. Funct Ecol 13:683-695. doi:10.1046/j.13652435.1999.00368.x

Romermann C, Tackenberg O, Jackel AK, Poschlod P (2008) Eutrophication and fragmentation are related to species' rate of decline but not to species rarity: results from a functional approach. Biodivers Conserv 17(3):591-604. doi:10.1007/ s10531-007-9283-21

Roumet C, Urcelay C, Díaz S (2006) Suites of root traits differ between annual and perennial species growing in the field. New Phytol 170:357-358. doi:10.1111/j.1469-8137.2006.01667.x

Ryser P, Urbas P (2000) Ecological significance of leaf life span among Central European grass species. Oikos 91:41-50. doi:10.1034/j.1600-0706.2000.910104.x

Sala OE, Parton WJ, Joyce LA, Lauenroth WK (1988) Primary production of the central grassland region of the United States. Ecology 69:40-45. doi:10.2307/1943158

Sasaki T, Okubo S, Okayasu T, Jamsran U, Ohkuro T, Takeuchi K (2009a) Management applicability of the intermediate disturbance hypothesis across Mongolian rangeland ecosystems. Ecol Appl 19(2):423-432. doi:10.1890/08-1850.1

Sasaki T, Okubo S, Okayasu T, Jamsran U, Ohkuro T, Takeuchi K (2009b) Two-phase functional redundancy in plant communities along a grazing gradient in Mongolian rangelands. Ecology 90 (9):2598-2608. doi:10.1890/08-0144.1

Saugier B, Roy J, Mooney HA (2001) Estimations of global terrestrial productivity: converging towards a single number? In: Roy J, Saugier B, Mooney HA (eds) Terrestrial global productivity. Academic, San Diego, pp 543-557

Schenk HJ, Jackson RB (2002) Rooting depths, lateral root spreads and below-ground/above-ground allometries of plants in waterlimited ecosystems. J Ecol 90:480-494. doi:10.1046/j.13652745.2002.00682.x

Schulze E-D, Zwölfer H (eds) (1987) Potential and limitations in ecosystem analysis. Springer, Berlin

Schulze E-D, Leuning R, Kelliher FM (1995) Environmental regulation of surface conductance for evaporation from vegetation. Vegetatio 121:79-87

Schulze E-D, Beck E, Müller-Hohenstein K (2005) Plant ecology. Springer, Berlin

Schumacher J, Roscher C (2009) Differential effects of functional traits on aboveground biomass in semi-natural grasslands. Oikos 118(11):1659-1668. doi:10.1111/j.1600-0706.2009.17711.x

Schuurman N, Leszczynski A (2008) Ontologies for bioinformatics. Bioinf Biol 2:187-200

Schwinning S, Ehleringer JR (2001) Water use trade-offs and optimal adaptations to pulse-driven arid ecosystems. J Ecol 89:464-480. doi:10.1046/j.1365-2745.2001.00576.x

Scurlock JMO, Johnson K, Olson RJ (2002) Estimating net primary productivity from grassland biomass dynamics measurements. Glob Change Biol 8:736-753. doi:10.1046/j.1365-2486.2002.00512.x

Shipley B (2010) From plant traits to vegetation structure. Chance and selection in the assembly of ecological communities. Cambridge University Press, Cambridge

Shipley B, Dion J (1992) The allometry of seed production in herbaceous angiosperms. Am Nat 139:467-483. doi:10.1086/285339
Shipley B, Vile D, Garnier E (2006) From plant traits to plant communities: a statistical mechanistic approach to biodiversity. Science 314:812-814. doi:10.1126/science.1131344

Silvertown J, Franco M, Harper JL (eds) (1997) Plant life histories. Ecology, phylogeny and evolution. Cambridge University Press, Cambridge

Small E (1972) Photosynthetic rates in relation to nitrogen recycling as an adaptation to nutrient deficiency in peat bog plants. Can J Bot 50:2227-2233

Smith RG (2006) Timing of tillage is an important filter on the assembly of weed communities. Weed Sci 54(4):705-712. doi:10.1614/WS-05-177R1.1

Smith CC, Fretwell SD (1974) The optimal balance between size and number of offspring. Am Nat 108:499-506. doi:10.1086/282929

Smith RG, Gross KL (2007) Assembly of weed communities along a crop diversity gradient. J Appl Ecol 44(5):1046-1056. doi:10.1111/j.1365-2664.2007.01335.x

Smith RG, Mortensen DA, Ryan MR (2009) A new hypothesis for the functional role of diversity in mediating resource pools and weed-crop competition in agroecosystems. Weed Res 50:37-48. doi:10.1111/j.1365-3180.2009.00745.x

Soons MB, Heil GW, Nathan R, Katul GG (2004) Determinants of long-distance seed dispersal by wind in grasslands. Ecology 85:3056-3068. doi:10.1890/03-0522

Stancioiu PT, O'Hara KL (2006) Leaf area and growth efficiency of regeneration in mixed species, multiaged forests of the Romanian Carpathians. For Ecol Manag 222(1-3):55-66. doi:10.1016/j. foreco.2005.10.018

Stein LD (2008) Towards a cyberinfrastructure for the biological sciences: progress, visions and challenges. Nat Rev Genet 9:678688. doi:10.1038/nrg2414

Stokes A, Atger C, Bengough AG, Fourcaud T, Sidle RC (2009) Desirable plant root traits for protecting natural and engineered slopes against landslides. Plant Soil 324(1-2):1-30. doi:10.1007/ s11104-009-0159-y

Storkey J (2006) A functional group approach to the management of UK arable weeds to support biological diversity. Weed Res 46 (6):513-522. doi:10.1111/j.1365-3180.2006.00528.x

Storkey J, Moss SR, Cussans JW (2010) Using assembly theory to explain changes in a weed flora in response to agricultural intensification. Weed Sci 58(1):39-46. doi:10.1614/ws-09-096.1

Stubbs WJ, Wilson JB (2004) Evidence for limiting similarity in a sand dune community. J Ecol 92(4):557-567. doi:10.1111/ j.0022-0477.2004.00898.x

Suding KN, Lavorel S, Chapin FS III, Cornelissen JHC, Díaz S, Garnier E, Goldberg DE, Hooper DU, Jackson ST, Navas M-L (2008) Scaling environmental change through the communitylevel: a trait-based response-and-effect framework for plants. Glob Change Biol 14:1125-1140. doi:10.1111/j.13652486.2008.01557.x

Swift MJ, Anderson JM (1993) Biodiversity and ecosystem function in agricultural systems. In: Schulze E-D, Mooney HA (eds) Biodiversity and ecosystem function. Springer, Berlin, pp 15-41

Tautenhahn S, Heilmeier H, Götzenberger L, Klotz S, Wirth C, Kühn I (2008) On the biogeography of seed mass in Germanydistribution patterns and environmental correlates. Ecography 31:457-468. doi:10.1111/j.2008.0906-7590.05439.x

Thompson K, Band SR, Hodgson JG (1993) Seed size and shape predict persistence in soil. Funct Ecol 7:236-241

Thompson K, Bakker JP, Bekker RM, Hodgson JG (1998) Ecological correlates of seed persistence in soil in the NW European flora. J Ecol 86:163-169. doi:10.1046/j.1365-2745.1998.00240.x

Thompson K, Askew AP, Grime JP, Dunnett NP, Willis AJ (2005) Biodiverstiy, ecosystem function and plant traits in mature and immature plant communities. Funct Ecol 19:355-358. doi:10.1111/j.1365-2435.2005.00936.x 
Thuiller W, Lavorel S, Midgley G, Lavergne S, Rebelo T (2004) Relating plant traits and species distributions along bioclimatic gradients for 88 Leucadendron taxa. Ecology 85(6):1688-1699. doi:10.1890/03-0148

Van Calster H, Vandenberghe R, Ruysen M, Verheyen K, Hermy M, Decocq G (2008) Unexpectedly high 20th century floristic losses in a rural landscape in northern France. J Ecol 96(5):927-936. doi:10.1111/j.1365-2745.2008.01412.x

van Wijk MT (2007) Predicting ecosystem functioning from plant traits: results from a multi-scale ecophysiological modeling approach. Ecol Model 203:453-463. doi:10.1016/j.ecolmodel.2006.12.007

Vanclay JK, Gillison AN, Keenan RJ (1997) Using plant functional attributes to quantify site productivity and growth patterns in mixed forests. For Ecol Manag 94(1-3):149-163. doi:10.1016/ S0378-1127(96)03972-2

Venable DL, Rees M (2009) The scaling of seed size. J Ecol 97:2731. doi:10.1111/j.1365-2745.2008.01461.x

Verbeek NAM, Boasson R (1995) Flowering height and postfloral elongation of flower stalks in 13 species of angiosperms. Can J Bot 73:723-727

Vila M, Vayreda J, Comas L, Ibanez JJ, Mata T, Obon B (2007) Species richness and wood production: a positive association in Mediterranean forests. Ecol Lett 10(3):241-250. doi:10.1111/ j.1461-0248.2007.01016.x

Vile D, Garnier E, Shipley B, Laurent G, Navas M-L, Roumet C, Lavorel S, Díaz S, Hodgson JG, Lloret F, Midgley GF, Poorter H, Rutherford MC, Wilson PJ, Wright IJ (2005) Specific leaf area and dry matter content estimate thickness in laminar leaves. Ann Bot 96:1129-1136. doi:10.1093/aob/mci264

Vile D, Shipley B, Garnier E (2006a) Ecosystem productivity can be predicted from potential relative growth rate and species abundance. Ecol Lett 9:1061-1067. doi:10.1111/j.1461-0248.2006.00958.x

Vile D, Shipley B, Garnier E (2006b) A structural equation model to integrate changes in functional strategies during old-field succession. Ecology 87:504-517. doi:10.1890/05-0822

Villeger S, Mason NWH, Mouillot D (2008) New multidimensional functional diversity indices for a multifaceted framework in functional ecology. Ecology 89(8):2290-2301. doi:10.1890/07-1206.1

Violle C, Lecoeur J, Navas M-L (2007a) How relevant are instantaneous measurements for assessing resource depletion under plant cover? A test on light and soil water availability in 18 herbaceous communities. Funct Ecol 21:185-190. doi:10.1111/j.1365-2435.2006.01241.x

Violle C, Navas M-L, Vile D, Kazakou E, Fortunel C, Hummel I, Garnier E (2007b) Let the concept of trait be functional! Oikos 116:882-892. doi:10.1111/j.2007.0030-1299.15559.x

Violle C, Garnier E, Lecœur J, Roumet C, Podeur C, Blanchard A, Navas M-L (2009) Competition, traits and resource depletion in plant communities. Oecologia 160:747-755. doi:10.1007/ s00442-009-1333-x

Vitousek PM, Hooper DU (1993) Biological diversity and terrestrial ecosystem biogeochemistry. In: Schulze E-D, Mooney HA (eds) Biodiversity and ecosystem function. Springer, Berlin, pp 3-14

Wahl S, Ryser P (2000) Root tissue structure is linked to ecological strategies of grasses. New Phytol 148:459-471. doi:10.1046/ j.1469-8137.2000.00775.x

Walker B, Kinzig A, Langridge J (1999) Plant attribute diversity, resilience, and ecosystem function: the nature and significance of dominant and minor species. Ecosystems 2:95-113

Walker KJ, Preston CD, Boon CR (2009) Fifty years of change in an area of intensive agriculture: plant trait responses to habitat modification and conservation, Bedfordshire. Engl Biodivers Conserv 18(13):3597-3613. doi:10.1007/s10531009-9662-y

Waller DM (1988) Plant morphology and reproduction. In: Lovett Doust J, Lovett Doust L (eds) Plant reproductive ecology patterns and strategies. Oxford University Press, New York, pp 203-227

Wardle DA (2002) Communities and ecosystems. Linking the aboveground and belowground components. Princeton University Press, Princeton

Wardle DA, Barker GM, Bonner KI, Nicholson KS (1998) Can comparative approaches based on plant ecophysiological traits predict the nature of biotic interactions and individual plant species effects in ecosystems? J Ecol 86:405-420. doi:10.1046/ j.1365-2745.1998.00268.x

Watanabe T, Broadley MR, Jansen S, White PJ, Takada J, Satake K, Takamatsu T, Tuah SJ, Osaki M (2007) Evolutionary control of leaf element composition in plants. New Phytol 174:516-523. doi:10.1111/j.1469-8137.2007.02078.x

Webb CO, Ackerly DD, McPeek MA, Donoghue MJ (2002) Phylogenies and community ecology. Annu Rev Ecol Syst 33:475-505. doi:10.1146/annurev.ecolsys.33.010802.150448

Weedon JT, Cornwell WK, Cornelissen JHC, Zanne AE, Wirth C, Coomes DA (2009) Global meta-analysis of wood decomposition rates: a role for trait variation among tree species? Ecol Lett 12:45-56. doi:10.1111/j.1461-0248.2008.01259.x

Weiher E, Keddy PA (1995) Assembly rules, null models, and trait dispersion: new questions front old patterns. Oikos 74(1):159164

Weiher E, Keddy P (1999) Ecological assembly rules. Perspectives, advances, retreats. Cambridge University Press, Cambridge

Weiher E, van der Werf A, Thompson K, Roderick M, Garnier E, Eriksson O (1999) Challenging Theophrastus: a common core list of plant traits for functional ecology. J Veg Sci 10:609-620. doi: $10.2307 / 3237076$

West GB, Brown JH, Enquist BJ (1997) A general model for the origin of allometric scaling laws in biology. Science 276:122126. doi:10.1126/science. 276.5309 .122

West GB, Brown JH, Enquist BJ (1999) A general model for the structure and allometry of plant vascular systems. Nature 400:664-667. doi:10.1038/23251

Westoby M (1998) A leaf-height-seed (LHS) plant ecology strategy scheme. Plant Soil 199:213-227. doi:10.1023/ A:1004327224729

Westoby M (1999) Generalization in functional plant ecology: the species sampling problem, plant ecology strategy schemes, and phylogeny. In: Pugnaire FI, Valladares F (eds) Handbook of functional plant ecology. Marcel Dekker, Inc, New York, pp $847-872$

Westoby M, Falster DS, Moles AT, Vesk PA, Wright IJ (2002) Plant ecological strategies: some leading dimensions of variation between species. Annu Rev Ecol Syst 33:125-159. doi:10.1146/annurev.ecolsys.33.010802.150452

Westoby M, Moles AT, Falster DS (2009) Evolutionary coordination between offspring size at independence and adult size. J Ecol 97 (1):23-26. doi:10.1111/j.1365-2745.2008.01396.x

Wezel A, Bellon S, Doré T, Francis C, Vallod D, David C (2009) Agroecology as a science, a movement and a practice. A review. Agron Sustain Devt 29:503-515. doi:10.1051/agro/2009004

Whittaker RH (1965) Dominance and diversity in land plant communities. Science 147:250-260. doi:10.1126/science.147.3655

Wilson JB (2007) Trait-divergence assembly rules have been demonstrated: limiting similarity lives! A reply to Grime. J Veg Sci 18(3):451-452. doi:10.1658/1100-9233(2007)18[451: TARHBD]2.0.CO;2

Wilson PJ, Thompson K, Hodgson JG (1999) Specific leaf area and leaf dry matter content as alternative predictors of plant strategies. New Phytol 143:155-162. doi:10.1046/j.14698137.1999.00427.x

Wirth C, Schumacher J, Schulze E-D (2004) Generic biomass functions for Norway spruce in Central Europe-a meta- 
analysis approach toward prediction and uncertainty estimation. Tree Physiol 24:121-139. doi:10.1093/treephys/24.2.121

Woodward FI, Diament AD (1991) Functional approaches to predicting the ecological effects of global change. Funct Ecol 5:202-212

Wright IJ (2001) Leaf economics of perennial species from sites contrasted on rainfall and soil nutrients. Division of Environment and Life Sciences, Macquarie University, Sydney, p 217

Wright IJ, Reich PB, Westoby M, Ackerly DD, Baruch Z, Bongers F, Cavender-Bares J, Chapin FS III, Cornelissen JHC, Diemer M, Flexas J, Garnier E, Groom PK, Gulias J, Hikosaka K, Lamont
BB, Lee T, Lee W, Lusk C, Midgley JJ, Navas M-L, Niinemets Ü, Oleksyn J, Osada N, Poorter H, Poot P, Prior L, Pyankov VI, Roumet C, Thomas SC, Tjoelker MG, Veneklaas E, Villar R (2004) The worldwide leaf economics spectrum. Nature 428:821-827. doi:10.1038/nature02403

Wright IJ, Reich PB, Cornelissen JHC, Falster DS, Garnier E, Hikosaka K, Lamont BB, Lee W, Oleksyn J, Osada N, Poorter H, Villar R, Warton DI, Westoby M (2005) Assessing the generality of global leaf trait relationships. New Phytol 166:485496. doi:10.1111./j.1469-8137.2005.01349.x 